\title{
Complex deformation in western Tibet revealed by anisotropic tomography
}

\author{
Heng Zhang,b,*, Junmeng Zhao ${ }^{a}$, Dapeng Zhao ${ }^{\mathrm{c}}$, Chunquan Yu ${ }^{\mathrm{b}}$, Hongbing Liu ${ }^{\mathrm{a}}$, \\ Zhaoguo Hu ${ }^{\text {d }}$
}

${ }^{a}$ Laboratory of Continental Collision and Plateau Uplift, Institute of Tibetan Plateau Research, Chinese Academy of Sciences, Beijing 100085, PR China.

E-mail: zhangheng415@itpcas.ac.cn

${ }^{\text {b }}$ Department of Earth, Atmospheric and Planetary Sciences, MIT, Cambridge, MA 01239, USA

${ }^{\text {c }}$ Department of Geophysics, Tohoku University, Sendai 980-8578, Japan

${ }^{\mathrm{d}}$ Shandong Zhengyuan Institute of Geological Exploration, China Central Bureau of Metallurgy and Geology, Jinan 250000, China

\begin{abstract}
The mechanism and pattern of deformation beneath western Tibet are still an issue of debate. In this work we present 3-D P- and S-wave velocity tomography as well as P-wave radial and azimuth anisotropy along the ANTILOPE-I profile and surrounding areas in western Tibet, which are determined by using a large number of $\mathrm{P}$ and $\mathrm{S}$ arrival-time data of local earthquakes and teleseismic events. Our result show that low-velocity (low-V) zones exist widely in the middle crust, whereas low-V zones are only visible in the lower crust beneath northwestern Tibet, indicating the existence of significant heterogeneities and complex flow there. In the upper mantle, a distinct
\end{abstract} 1 
low-V gap exists between the Indian and Asian plates. Considering the P- and S-wave tomography and P-wave azimuthal and radial anisotropy results, we interpret the gap to be caused mainly by shear heating. Depth-independent azimuthal anisotropy and high-velocity zones exist beneath the northern part of the study region, suggesting a vertically coherent deformation beneath the Tarim Basin. In contrast, tomographic and anisotropic features change with depth beneath the central and southern parts of the study region, which reflects depth-dependent (or decoupled) deformations there. At the northern edge of the Indian lithospheric mantle (ILM), P-wave azimuthal anisotropy shows a nearly east-west fast-velocity direction, suggesting that the ILM was re-built by mantle materials flowing to the north.

\section{Introduction}

Although many controversial issues remain in the geodynamic models about the Tibetan plateau, the northward subduction of the Indian plate has been certainly playing a key role during the formation of the plateau. By using different techniques and data sets collected from several seismic experiments, such as the PASSCAL, INDEPTH, Hi-CLIMB, Namche Barwa, TW-80 and TIBET-31N, a number of seismic studies have been made to detect the subducting Indian plate beneath the Tibetan plateau and surrounding regions. Because of the complex structures of the Tibetan plateau and the sparse seismometer deployment, there are still many disputes on the northern limit and detailed deformation pattern of the Indian lithospheric mantle (ILM), e.g., whether the ILM is downwelling at the Bangong-Nujiang suture in 
central Tibet (Tilmann et al., 2003), whether the sub-horizontal ILM is underthrusting to the Jinsha River suture in western Tibet (Zhao et al., 2010), and whether the whole Tibet is underlain by relatively high-velocity materials (Priestley et al., 2006). Seismic anisotropy has been observed in various parts of the Earth's interior, including the crust, the upper mantle, the transition zone, the D" layer, and the inner core. Studies of seismic anisotropy can provide important constraints on both the past and present-day deformations beneath the Tibetan plateau. In general, the convergence of continents can cause strong deformations. Seismic anisotropy has been used to reveal the deformations and to identify the boundary between the ILM and the Eurasian lithospheric mantle (Huang et al., 2000).

The following geophysical features have been revealed in the Tibetan Plateau: (1) $\mathrm{P}$ and $\mathrm{S}$ wave velocities (Vp, Vs) are low in the north but high in the south (e.g., Zhang et al., 2012a; Zhang et al., 2012b); (2) Sn-wave generation is inefficient in the north but efficient in the south (Rapine et al., 1997); (3) seismic anisotropy is strong in the north but weak in the south (Huang et al., 2000). These features reflect strong lateral heterogeneities beneath the Tibetan Plateau, but their causes are still not very clear.

The geophysical results obtained so far are usually not consistent with each other, indicating that our understanding of the evolution of the Tibetan plateau is still incomplete. To date, most of the research projects have carried out geophysical observations in central and eastern Tibet, whereas there have been few such observations in western Tibet. In this study, we apply P-wave anisotropic tomography 
to the data recorded by the seismic stations deployed along the ANTILOPE-I (Array Network of Tibetan International Lithospheric Observation and Probe Experiment) profile in western Tibet and the southern Tarim basin (Fig. 1). Our results shed new light on the extending distances and properties of the Indian and Eurasian plates, as well as the deformation mode in the crust and upper mantle beneath western Tibet.

\section{Data and method}

\subsection{Data selection}

We used well-located local and teleseismic events recorded at 68 portable seismic stations of the ANTILOPE-I profile, which were deployed from October 2006 to November 2007 (Fig. 1). We manually picked up P- and S-wave arrival times (including Pg, Pn, P, Sg, Sn, and S phases) using the Crazyseismic software which is based on the waveform cross-correlation (Yu et al., 2016). By performing different frequency band-filtering, the picking accuracy is estimated to be $0.1-0.2 \mathrm{~s}$ for P-wave data and 0.2-0.3 s for S-wave data. Theoretical travel times are calculated using the iasp91 Earth model (Kennett and Engdahl, 1991) for the upper mantle and a modified CRUST1.0 model (Laske et al., 2013) for the crust (Fig. 2a). Hypocentral parameters of the teleseismic events were determined by the United States Geological Survey, whereas those of the local and regional events were determined by the China Earthquake Network Center (CENC). The selected teleseismic events have magnitudes greater than 5.5, and their epicentral distances are restricted between $30^{\circ}$ and $90^{\circ}$ from the center of the study area (Figs. $1 \mathrm{~b}$ and $1 \mathrm{c}$ ). For the local earthquakes, 
we selected only the events with magnitudes greater than 4.0, and we eliminated those poorly located events with a fixed focal depth of $33 \mathrm{~km}$ by the CENC. It was difficult to identify the precise arrivals of local earthquakes, hence we bandpass-filtered the original seismograms in different frequencies and adopted the average arrival time in the inversion. In addition, we only collected those arrival times with a clear onset, and all the phases used in this study are the first arrivals. In practice, the complex geometry of the Moho discontinuity and velocity variations in the lower crust beneath the study region often make it hard to distinguish the upper-mantle P-wave arrivals from the Pn-wave arrivals. Therefore, we took several processing steps to measure Pn and Sn arrival times (Hearn, 1996). The Pn and Sn data were collected based on the following criteria: (1) epicentral distances between $3^{\circ} \sim 11^{\circ}$; (2) the focal depth is smaller than the Moho depth which is determined from the CRUST1.0 model; (3) the Pn wave travel-time residual is $<4 \mathrm{~s}$ (and $<5 \mathrm{~s}$ for Sn wave) after a straight line fit; (4) each event was recorded by at least 8 stations; and (5) each station recorded at least 8 local or regional events. The maximum epicentral distance is restricted to $11^{\circ}$, because the travel-time residuals for the initial velocity model form a straight line up to $11^{\circ}$ in a residual-distance plot. The minimum epicentral distance is restricted to $3^{\circ}$ rather than $1.5^{\circ}$ because of the thick crust beneath Tibet.

The $\mathrm{Vp} / \mathrm{Vs}$ ratio is calculated directly from the separate $\mathrm{Vp}$ and Vs models in an area with a good ray coverage for both $\mathrm{P}$ and $\mathrm{S}$ waves. Differences in the coverage of P- and S-wave rays can lead to different resolutions of Vp and Vs models, which may result in uncertainties in $\mathrm{Vp} / \mathrm{Vs}$ ratio. Hence, we chose only those events which have 
both of clear P- and S-wave arrivals.

As a result, our data set consists of $9560 \mathrm{P}$-wave arrivals and $8541 \mathrm{~S}$-wave arrivals from 583 local earthquakes (Fig. 1a), as well as 11,183 P-wave arrivals and 10,565 S-wave arrivals from 611 teleseismic events (Figs. 1b and 1c). Although the number of P-wave data is not the same as that of S-wave data, they have very similar ray distributions. That is, the $\mathrm{P}$ - and $\mathrm{S}$-wave data share nearly identical source-receiver paths.

\subsection{P-wave tomography for 3-D azimuthal anisotropy}

We used the anisotropic tomography method (Wang and Zhao, 2008, 2013) which was developed from the isotropic tomography method by Zhao et al. $(1992,1994)$. Under the assumption of azimuthal anisotropy with a horizontal axis of hexagonal symmetry, the P-wave slowness can be expressed as:

$$
\mathrm{S}(\varphi)=\mathrm{S} 0[1+\mathrm{A} \cos (2 \varphi)+\mathrm{B} \sin (2 \varphi)]
$$

where $\mathrm{S}$ is the total slowness, $\mathrm{S}_{0}$ is the azimuthal average slowness, $\mathrm{A}$ and $\mathrm{B}$ are two azimuthal anisotropy parameters, and $\varphi$ is the ray path azimuth. The fast-velocity direction $(\mathrm{FVD}, \psi)$ and the amplitude $(\alpha)$ of azimuthal anisotropy are expressed as

$$
\Psi=\left\{\begin{array}{c}
\frac{1}{2} \tan ^{-1} \frac{B}{A}+\left\{\begin{array}{cc}
\frac{\pi}{2}, & A>0 \\
0, & A<0
\end{array},\right. \\
-\frac{\pi}{4}, A=0, B>0 \\
\frac{\pi}{4}, A=0, B<0 \\
\alpha=\frac{V_{f}-V_{s}}{2 V_{0}}=\frac{\sqrt{A^{2}+B^{2}}}{1-\left(A^{2}+B^{2}\right)},
\end{array}\right.
$$

where $\mathrm{V}_{0}$ denotes the average isotropic velocity, $\mathrm{V}_{\mathrm{f}}$ and $\mathrm{Vs}$ denote the velocities in the 
fast and slow directions, respectively. For details of the method, see Wang and Zhao (2008, 2013) and Zhao (2015).

\subsection{P-wave tomography for 3-D radial anisotropy}

Following the formation of Wang and Zhao (2013) with a vertical axis of hexagonal symmetry, the P-wave slowness can be expressed as,

$$
S=S_{0}[1+M \cos (2 \theta)]
$$

where $\mathrm{S}$ is the total slowness, $\mathrm{S}_{0}$ is the isotropic slowness, $\mathrm{M}$ is a parameter for radial anisotropy, and $\theta$ is the incident angle of a ray path. The amplitude $\beta$ of radial anisotropy is expressed as

$$
\beta=\frac{\mathrm{V}_{\mathrm{ph}}-\mathrm{V}_{\mathrm{pv}}}{2 \mathrm{~V}_{0}}=\frac{\mathrm{M}}{1-\left(\mathrm{M}^{2}\right)},
$$

where $\mathrm{Vp}_{\mathrm{h}}$ and $\mathrm{Vp}_{\mathrm{v}}$ are $\mathrm{P}$-wave velocities in the horizontal and vertical directions, respectively, and $V_{0}$ is the isotropic velocity. Thus, $\beta>0$ indicates a faster $\mathrm{P}$-wave velocity in the horizontal direction, i.e., $\mathrm{Vp}_{\mathrm{h}} / \mathrm{Vp}_{\mathrm{v}}>1$. For details of this method, see Wang and Zhao (2013) and Zhao (2015).

\subsection{Model setup and inversion}

Two sets of 3-D grid are arranged in the modeling space (Figs. 2b, 2c and 2d). A fine grid is used to express the 3-D isotropic Vp structure, and a relatively coarse grid is adopted to express the anisotropic Vp structure, because a better azimuthal coverage of seismic rays is required to invert for the anisotropic parameters. After many tests, we found that the optimal grid interval for our data set is $0.5^{\circ}$ and $1^{\circ}$ in the lateral direction (but $1^{\circ} \sim 2^{\circ}$ at the edges of the model) for the fine and coarse grids, 
respectively. The vertical grid interval is $15-50 \mathrm{~km}$ for both grids. Our 3-D model contains two layers separated by the Moho discontinuity, and the Moho geometry is derived from our previous result (Zhao et al., 2010, the black dashed line in Fig. 2c) and the CRUST1.0 model. The crustal and mantle velocities are assigned to the grid nodes located in the upper and lower layers, respectively. For the local earthquakes with epicentral distances of $3^{\circ}$ to $11^{\circ}$, the Pn phases are hard to distinguish from the mantle $\mathrm{P}$ phases due to their similar waveforms and travel times. Hence, we calculated theoretical travel times for both waves, and the wave with a smaller travel-time residual is adopted in the inversion. To examine the effect of this problem, we conducted another inversion by adopting the wave (i.e., Pn or the mantle P wave) with a larger travel-time residual in the inversion. Comparing the results of the two inversions (Figs. 3 and S2), we can see that their overall patterns are almost the same. The reason for the similar results is that these two types of waves share similar ray paths and the difference between their travel times is very small. The LSQR algorithm (Paige and Saunders, 1982) with damping and smoothing regularizations (Wang and Zhao, 2013) is used to conduct tomographic inversions.

\section{Results and resolution tests}

\subsection{Seismic velocity images}

Figures 3 and 4 show map views of $\mathrm{Vp}$ azimuthal and radial anisotropy tomography beneath western Tibet (more images are shown in the Supporting Information). The red and blue colors denote low-velocity (low-V) and high-velocity (high-V) zones, respectively, relative to the starting 1-D iasp91 model for the mantle 
and the CRUST1.0 model for the crust. Because the velocity and anisotropic parameters at the grid nodes are taken as unknown parameters and their perturbation at any point in the model is calculated by linearly interpolating their perturbations at the eight grid nodes surrounding that point, their perturbation changes across the Moho are not so strong. However, obvious vertical smearing occurs in areas where the resolution is low. Low-V zones are visible beneath northwestern Tibet, whereas two high-V zones appear beneath the Tarim Basin and the southern part of the profile. Although details of the velocity anomalies change with depth, e.g., low-V zones prevail at $35 \mathrm{~km}$ depth and high-V zones become prominent at $100 \mathrm{~km}$ depth, the western Tibetan plateau seems to consist of three parts. The travel-time residuals from the southern and northern events reflect the velocity anomalies in those areas (Fig. 5). The Vs tomography shows the same pattern as that of Vp tomography, although the amplitude of velocity anomalies shows some differences. The perturbation of $\mathrm{Vp} / \mathrm{Vs}$ ratio $(\delta r)$ can be expressed as follows:

$$
\delta r=\left(\frac{(1+\delta V p) V p}{(1+\delta V s) V s}-\frac{V p}{V s}\right) / \frac{V p}{V s}=\frac{\delta V p-\delta V s}{1+\delta V s},
$$

where $\delta V p$ and $\delta V s$ are perturbations of $\mathrm{Vp}$ and $\mathrm{Vs}$, respectively. A larger $\mathrm{Vp} / \mathrm{Vs}$ in the lower crust under southwestern Tibet is a direct result of a higher Vp there. In contrast, a larger $\mathrm{Vp} / \mathrm{Vs}$ in the upper mantle beneath southwestern Tibet is attributed to a lower Vs there.

Two prominent features are visible in the Vp and Vs images (Fig. 6a and 6b). One is that, in the upper mantle, two high- $\mathrm{V}$ zones are separated by an obvious low-V anomaly. The other feature is that high- $\mathrm{V}$ zones exist in the lower crust except for the 
Qiangtang block. A dipping zone of low Vp/Vs is visible at depths of 100 and $200 \mathrm{~km}$ (Fig. 6c). In addition, more local earthquakes occurred in areas with a low $\mathrm{Vp} / \mathrm{Vs}$ ratio.

\subsection{Azimuthal and radial anisotropy}

The pattern of $\mathrm{Vp}$ azimuthal anisotropy beneath western Tibet changes significantly with depth (Fig. 3a). The amplitude of azimuthal anisotropy beneath the Gozha-Longmu Co fault becomes larger as depth increase to $55 \mathrm{~km}$, and the FVDs are generally parallel with the Gozha-Longmu Co fault orientation. At depths of 100 and $150 \mathrm{~km}$, the FVDs beneath the Tarim basin are similar to those in the lower crust, but the FVDs in the Qiangtang block change from ENE to nearly E-W and ESE. Higher $\mathrm{V}_{\mathrm{p}}$ is associated with a nearly N-S FVD in the uppermost mantle, and a different FVD appears near the BNS at $150 \mathrm{~km}$ depth. At depths $>150 \mathrm{~km}$, the anisotropy becomes weak (Fig. 3).

The results of radial anisotropy in map views and in a vertical cross-section along $82^{\circ} \mathrm{E}$ are shown in Figures $4 \mathrm{~b}$ and $6 \mathrm{e}$, respectively. The brown colour indicates positive radial anisotropy, i.e., $\mathrm{V}_{\mathrm{ph}} / \mathrm{V}_{\mathrm{pv}}>1$, whereas the green colour indicates negative radial anisotropy, i.e., $\mathrm{V}_{\mathrm{ph}} / \mathrm{V}_{\mathrm{pv}}<1$. In the middle crust, the radial anisotropy beneath the Tibetan Plateau is generally positive, whereas strong negative radial anisotropies are visible in the lower crust of the southern Qiangtang block and the Songpan-ganzi block. Below the Moho discontinuity, positive anisotropies are revealed in most of the study region, with noticeable isolated anomalies in the Tarim basin and to the south of the Indus-Tsangpo suture. At a depth of $150 \mathrm{~km}$, the 
anisotropy becomes weak and a negative radial anisotropy extends to the Lhasa block.

\subsection{Resolution tests}

Both checkerboard and synthetic tests (Zhao et al., 1992) are conducted to evaluate the resolution of our tomographic images. To conduct the checkerboard test, negative and positive velocity variations and anisotropies $( \pm 5 \%)$ are alternatively added to the neighboring grid nodes to make a checkerboard input model, and then synthetic travel times are computed for the input checkerboard model. To simulate the picking errors in the observed data, we add random noise $( \pm 0.1 \mathrm{~s}$ for P-wave and $\pm 0.2 \mathrm{~s}$ for $\mathrm{S}$-wave) to the synthetic data, and use the same algorithm as for the observed data to invert the synthetic data. The areas where the input checkerboard pattern is well recovered are considered to have a good resolution. Our test results show that velocity anomalies with a grid interval of $\sim 1^{\circ}$ could be recovered and most parts of our study area are well resolved, especially along the ANTILOPE-I profile (Fig. 7). More checkerboard test results are shown in the Supporting Information. Not only the eastern part but also the western part of our study region exhibit good resolutions, because we used many intermediate-depth earthquakes (>100 km depth) beneath the Pamir plateau and Hindu Kush (see Fig. 1a). Note that the resolution at $200 \mathrm{~km}$ depth is relatively low, because local seismic rays rarely go through that depth and the teleseismic ray coverage is very limited there (Figs. S3-S5). Considering the azimuthal coverage of our P-wave data (Fig. S6), we focus our discussion on the results in the shallower areas $(<200 \mathrm{~km}$ depth $)$.

Smearing may occur in both vertical and horizontal directions in a velocity 
transition zone, especially near the Moho discontinuity, due to the large variations in its velocity and geometry. The $\cos (2 \phi)$ and $\sin (2 \phi)$ variations in $\mathrm{Vp}$ are periodic in $\pi$ (see Equation 1), and our P-wave ray distribution is dense enough at most grid nodes to resolve the $2 \phi$ azimuthal variations. The results of our synthetic tests show that most parts of the study region are well resolved, but smearing occurs in the following areas and features: (1) the velocity image below $150 \mathrm{~km}$ depth under the Tarim basin and the extent of the high-V zone beneath the Songpan-Ganzi basin; (2) the FVDs in the lower crust of the western Songpan-Ganzi and Tarim blocks and at $150 \mathrm{~km}$ depth beneath the western Tarim basin and the Songpan-Ganzi block, which are marked as red rectangles in Figs. S19 and S20); and (3) the radial anisotropy at $150 \mathrm{~km}$ depth beneath the Lhasa block. In addition to the checkerboard and synthetic tests as mentioned above, we have conducted several more inversions with different starting velocity models. These inversion results show that the main features of our tomographic results are quite robust. Although our tomographic model covers a wide region, in the following we focus our discussion on the central area because the resolution is the best in the central area, whereas the resolution is lower in the edge parts (for details of the resolution tests, see the Supporting Information).

\section{Discussion}

\subsection{Crustal structure}

From the south to the north, our study region consists of the Lhasa block (LB), the Qiangtang block (QB), the Songpan-Ganzi block (SB), and the Tarim basin (TB). The Lhasa block is located between the Indus-Tsangpo suture (ITS) and the 
Bangong-Nujiang suture (BNS). The Jurassic strata were detected in the northern Lhasa block, and the Cretaceous to Tertiary Gangdese batholith intruded to the Paleozoic and Mesozoic sequences of the southern Lhasa block (Yin and Harrison, 2000). The Qiangtang block is bounded by the BNS and the Jinsha River suture (JRS). Combining the results of $40 \mathrm{Ar} / 39 \mathrm{Ar}$, structure and thermobarometry, Kapp et al. (2003) suggested that the deeper crust of the Qiangtang block includes the early Mesozoic mélange which is translated from the southward subduction of the Sonpan-Ganzi block. The Sonpan-Ganzi block, which is located between the Tarim basin to the north and the Qiangtang block to the south, comprises a large volume of the Triassic strata. These strata are usually considered as the Songpan-Ganzi flysch complex, and many lines of evidence show strong connections between the Songpan-Ganzi flysch complex and the Qinlin-Dabie orogen (Yin and Harrison, 2000). To the north of the Altyn Tagh fault (ATF), the Tarim basin has a Precambrian basement which is much older than that in the Tibetan plateau (Xu et al., 2013). The Gozha-Longmu Co fault was produced by reconstruction of the southwestern ATF and the southern Karakoram fault during the late Miocene to Pliocene (Raterman et al., 2007), and in this study we assume it as the westward extension of the ATF (Fig. 1).

Although geological interpretations of the geophysical results are usually not unique, our results show strong lateral and vertical structural variations which are similar to the geological features in the study region. The Songpan-Ganzi flysch, which exists widely in the SB and the northern $\mathrm{QB}$, could significantly lower the seismic velocity and cause a higher $\mathrm{Vp} / \mathrm{Vs}$ ratio (Figs. 3 and 4). A high-V zone is 
located directly below the Gangdese batholith in the Lhasa block. A high-V anomaly detected in the middle to lower crust of the Tarim basin coincides with the old and cold Precambrian basement (Xu et al., 2013). Note that isotropic velocity variations only reflect the underground structure at present, whereas seismic anisotropy can provide information on the past deformations over a long geological period (Yin and Harrison, 2000). For example, although high-V anomalies exist in both the Tarim basin and the Lhasa block, their different FVDs may indicate varied deformation patterns in the two regions, which are discussed in the following sections.

Previous studies have shown that low-V zones exist widely in the middle and/or the lower crust, which permit the crustal flow (Clark and Royden, 2000). McKenzie and Priestley (2008) argued that radiogenic heat production in the thickened Tibetan crust may heat the mid-crust, which eventually heats the lower crust and the uppermost mantle. This process could cause a temperature reverse, resulting in a highest temperature in the middle crust and a negative temperature gradient. This heating could also elevate the temperatures of the underlying ILM to $\sim 120 \mathrm{~km}$ depth (Craig et al., 2012). This interpretation seems only reasonable to the north of $34^{\circ} \mathrm{N}$, including the northern QB and SB, because obvious low-V zones extend to the upper mantle. In the south of $34^{\circ} \mathrm{N}$, pervasive high- $\mathrm{V}$ anomalies exist in the lower crust, reflecting that the radiogenic heat is suppressed or the heating source is different. The lower crust eclogitization is a possible cause of the high-V zones, because eclogite generally has a higher $\mathrm{Vp}$ than that of the uppermost mantle. A receiver-function image, which is located very close to our profile, indicates a progressively eclogitized 
lower crust (Zhang et al., 2014).

Azimuthal anisotropy occurs throughout the QB interior with ENE-WSW FVDs, which is supported by the result of shear-wave splitting in the adjacent region (Wu et al., 2015). However, the FVDs in the SB lower crust are nearly parallel to the GLF, which can be partly explained by a NE-SW extension contemporaneous with magmatism in the Miocene at the western part of the GLF (Van Buer et al., 2015). Another striking feature in the crust is the $\mathrm{N}-\mathrm{S}$ trending negative radial anisotropy and a weak azimuthal anisotropy beneath the Lunggar rift (Fig. 4b). The negative radial anisotropy at a depth of $55 \mathrm{~km}$ in the vicinity of the GLF reflects a feature in the uppermost mantle rather than in the crust. C-type olivine, induced by high water content (Karato et al., 2008), is probably dominant in the upwelling beneath northern Tibet, leading to the negative radial anisotropy. Styron et al. (2015) suggested slower eastward flow in northern Tibet but flowing with a high magnitude in the south because of the thickening lower crust. This model can explain the weak azimuthal anisotropy in the Lhasa block. Considering the different velocity anomalies and anisotropic features, we suppose that the formation mechanisms of the two detachment systems should be different, although the recently active GLF and Lunggar rift are confined to the upper crust (Kapp et al., 2008; Van Buer et al., 2015). However, a discussion on the particular mechanisms of the faults is beyond the scope of this work.

\subsection{Upper mantle structure}

A slab-like anomaly with high- $\mathrm{V}_{\mathrm{p}}$, high- $\mathrm{V}_{\mathrm{s}}$ and low- $\mathrm{V}_{\mathrm{p}} / \mathrm{V}_{\mathrm{s}}$ (Fig. 6) beneath Tibet 
is usually interpreted as the Indian lithospheric mantle. Mineral physics results showed that the $\mathrm{V}_{\mathrm{P}} / \mathrm{V}_{\mathrm{S}}$ ratio is negatively related with $\mathrm{Mg \#}$ (magnesium number); hence it is expected that $V_{P} / V_{S}$ is low in depleted mantle materials (Lee, 2003). A $400^{\circ} \mathrm{C}$ decrease of temperature in the upper mantle would cause $\sim 0.5 \%$ change in the $\mathrm{V}_{\mathrm{p}} / \mathrm{V}_{\mathrm{S}}$ ratio, which is much smaller than the observed value $(\sim 2 \%)$. Such a low $\mathrm{V}_{\mathrm{p}} / \mathrm{V}_{\mathrm{s}}$ value requires a compositional change, which could be interpreted as a refractory mantle depleted of volatiles (Hacker and Abers, 2004). Our resolution tests show that the northern edge of the high-V zone is restricted to $\sim 34^{\circ} \mathrm{N}$. Teleseismic receiver-function results suggested that the Indian plate may have reached as far as the BNS, and possibly as far north as the ATF beneath the western Tibet (Wittlinger et al., 2004). A travel-time tomography revealed that the Indian plate has underthrusted beneath the western Tibet at least to $32.5^{\circ} \mathrm{N}$ (Razi et al., 2014). Following our previous interpretation (Zhao et al., 2010) and the present results of Vp azimuthal anisotropy, we speculate that the ILM has underthrusted northward to the JRS.

North of the ILM, the upper mantle beneath the QB and SB is characterized by a high $\mathrm{V}_{\mathrm{p}} / \mathrm{V}_{\mathrm{s}}$ ratio, which may reflect a warm upper mantle. A different anisotropic pattern in the north may be related to a presently non-subduction zone, where the fabric has a fast direction perpendicular to the convergence direction. The heating source could be the northern Tibetan lithosphere squeezed and sheared between the advancing ILM and the rigid Tarim lithosphere (Huang et al., 2000), and it could also be attributed to mantle upwelling induced by the northward subducting ILM (Tilmann et al., 2003). The nearly E-W trending FVDs, strong positive radial anisotropy, and 
subhorizontal underthrusting ILM support a mechanism of shear heating down to a depth of $100 \mathrm{~km}$.

Simple shearing is probably the primary type of deformation in the upper mantle. A long-term northward movement of the Indian continent would generate a fast orientation trending N-S rather than E-W. However, regions with high water content could produce type- $\mathrm{B}$ or type- $\mathrm{C}$ fabric, leading to a trench-parallel polarization direction (Karato et al., 2008). Although such a water-rich region is not common in the upper mantle, it is plausible if mantle upwelling exists. The lower sub-continental lithosphere convection beneath northern Tibet may induce asthenospheric upwelling. However, there is a timescale for crystal alignment along the flow, and the fast axis may not have enough time to adapt the rapid change in the flow direction. The upper mantle may preserve fabric with its fast direction parallel to the subducting slab. In addition to the anisotropy, the strong negative anomaly of $\mathrm{V}_{\mathrm{P}} / \mathrm{V}_{\mathrm{S}}$ does not extend as far north as the high- $\mathrm{V}$ zones of $\mathrm{V}_{\mathrm{P}}$ and $\mathrm{V}_{\mathrm{S}}$ (only a weaker and thinner anomaly extends to $\sim 34^{\circ} \mathrm{N}$ ). Taking into account the different modes of radial anisotropy within the ILM, we think that the northernmost part of the ILM with distinct characterizations has been reconstructed by the materials to the north.

\subsection{Crust-mantle interactions}

The eclogitization or partial eclogitization could explain the high- $\mathrm{V}$ zones in the lower crust, but the high-V zones with different anisotropies beneath the LB and the QB in the upper to middle crust need more analysis. The Neo-Tethyan slab rollback should have enhanced the asthenospheric corner flow and changed the thermal 
structure of the mantle wedge (Chung et al., 2005). In the mantle wedge, the fast directions may be due to the dominance of trench-parallel mantle wedge flow or complex flow in many subduction zones (Tian and Zhao, 2012; Liu et al., 2013; Niu et al., 2016; Zhao et al., 2016). Experimental studies showed that the polarization direction near the trench is parallel to the trench because of the high water content and high stress in these environments producing the type-B fabric, and the effect may extend to $\sim 200 \mathrm{~km}$ depth (Karato et al., 2008). The young ages of granitic dikes near the GLF suggest that footwall rocks remained hot until the late Miocene (Van Buer et al., 2015). This result may partly explain the absence of high-V zones in the lower crust beneath the northern QB. These results suggest that the high-V zone in the southern QB may keep the frozen-in anisotropy which was produced by vertical growth (mantle upwelling) and lateral extension (trench-parallel mantle wedge flow).

In contrast, a weak azimuthal anisotropy associated with both high- $\mathrm{V}$ and low-V zones appears in the southern LB. The degree of eclogitization increasing from the southern LB to the northern LB (Zhang et al., 2014) and local weakening of the crustal flow (Wu et al., 2015) were detected in this region, implying different crustal structures. One explanation is vertical deformation caused by crustal thickening and shortening (England and Houseman, 1986), but our azimuthal anisotropy tomography could not resolve this feature because a vertical symmetry axis is assumed. The process of accreted Indian crust accompanied with the ILM underthrusting could result in tilted or near-vertical slow-axis anisotropy. An alternative interpretation is 
that obvious anisotropy may not be observed in western Tibet if the deformation has initiated in only the past 2 3 Ma (Taylor and Peltzer, 2006).

All these features suggest that western Tibet could be divided into three segments with different deformation patterns (Fig. 8), which are the decoupled segment (the LB), the partly decoupled segment (the QB and the SB), and the coupled segment (the Tarim basin). Considering the low resolution of the crustal tomography beneath the TB and the SB, the coupled or decoupled model may only explain the processes between the lower crust and the upper mantle. In addition, the coupled segment should be only restricted to the eastern part, because significant smearing occurs in the western part (see Figs. S19 and S20. Note that the feature at $55 \mathrm{~km}$ depth beneath the Tarim basin is related to the uppermost mantle rather than the lower crust). Beneath the LB, our azimuthal anisotropy results show a decoupled deformation between the crust and the uppermost mantle, though their velocity anomalies look similar. Unlike the orogen-parallel anisotropy, the weak anisotropy in Tibet may reflect a vertical or a recent deformation as mentioned above.

In the partly decoupled part, although the amplitudes of azimuthal anisotropy are roughly the same, our results show that the FVDs are not similar in the crust. The distinct FVDs in the crust and upper mantle suggest that the GLF, the westward continuation of the ATF, does not extend to over $100 \mathrm{~km}$ depth. More importantly, the GLF may generate partial melting, which may explain the different velocities in the lower crust beneath the QB and the SB. The shear heating, as mentioned in the last section, is not the only cause of the low-V zone beneath the SB, because its radial 
anisotropy, FVDs and velocity variations in the upper mantle are almost the same as those beneath the QB. A magnetotelluric study proposed that the ATF system is characterized by a deep fluid-rich zone, and the faults act as a pathway for the upward migration of the fluids (Zhang et al., 2015). Our present results suggest that the western ATF causes different FVDs in the crust and becomes a tunnel to mingle the materials from the upper mantle and the crust, which could further induce partial melting. The azimuthal anisotropy and velocity anomalies in the crust of western Tibet also imply that crustal materials are hard to flow in the LB and the lower crust under the QB, but they are easier to extrude eastward in the SB lower crust and the QB middle crust. The nearly E-W trending azimuthal anisotropy is consistent with the Tibet conjugate zone, implying an eastward spreading in the Tibetan crust (Taylor et al., 2003). However, the azimuthal anisotropy and velocity anomalies do not support the model of pervasive crustal flow in western Tibet. In addition, an updated model on the formation of the V-shaped conjugate faults has emphasized the importance of eastward flow of asthenosphere and eastward spreading of the Tibetan lithosphere (Yin and Taylor, 2011).

Coupled deformations occurred beneath the Tarim basin, suggesting that it is a rigid block. Because of the weak materials beneath the $\mathrm{QB}$ and the $\mathrm{SB}$, it seems that the push force of the northward underthrusting Indian plate could not rotate the Tarim basin clockwise. The clockwise rotation of the Tarim basin requires stronger push in the west than in the east (Avouac et al., 1993). In other words, the Indian plate almost contacts the Eurasian continent to the west of our profile. Although there are still 
debates on whether the Tarim lithosphere subducts beneath Tibet (Wittlinger et al., 2004) or the ILM underthrusts directly beneath the Tarim (Priestley et al., 2006), regional seismicity between $76^{\circ} \mathrm{E}$ and $82^{\circ} \mathrm{E}$ supports the conclusion that the ILM abuts the Tarim lithosphere, with intermediate-depth earthquakes occurring at depths of $100 \sim 200 \mathrm{~km}$. Towards the east, much of the convergence is absorbed south of the Tarim basin or transferred eastwards (Avouac et al., 1993). Furthermore, the weak materials of the QB and SB between the ILM and the Tarim lithosphere may play an important role in increasing the slip rate along the ATF, because the current slip rate at the Karakax fault seems much smaller than that along the ATF at present (Furuya and Yasuda, 2011). In this scenario, the weak materials can be viewed as a catalyst for the clockwise rotation of the Tarim basin, because the Tarim basin is hard to rotate if the rigid ILM directly encounters the stable Tarim lithosphere. In other words, the weak materials form a gap or space for the Tarim rotation.

The convergence between the western Indian plate and the Eurasian plate is accommodated by a combination of shortening in the south, extruding in the central and rotating in the north. The movement of India and Tarim cannot be completely coupled in the NW Tibet due to their different surface velocities measured by GPS (Craig et al., 2012). It is possible that a "lubricating" layer, sandwiched by the advancing ILM in the south and the rigid Tarim lithosphere in the north, is not only a passive layer being squeezed but also affects the structure of the ILM and probably provides the Tarim basin with an adaptable environment to rotate. V-shaped conjugate faults, which are caused by eastward flow of the asthenosphere together with the 
eastward spreading Tibetan lithosphere, are abundant in the central part of central Tibet (Yin and Taylor, 2011). The absence of E-W FVDs and prevailed high-V zones in southwestern Tibet may explain the rare $\mathrm{V}$-shaped conjugate faults in that area $(\mathrm{Wu}$ et al., 2015). One unresolved issue is what mechanism caused the partly decoupled deformation between the crust and the upper mantle beneath the QB and the SB. The lower crust (partial) eclogitization, different causes of the high-V zones in the crust, and the impact of main faults are three possibilities.

\section{Conclusions}

$\mathrm{P}$ and $\mathrm{S}$ wave tomography and $\mathrm{P}$-wave anisotropy along a north-south trending profile in the western Tibetan plateau reveal significant lateral heterogeneities and diverse deformation patterns. This region can be divided into three segments from the south to the north, including the decoupled part in central-southern Tibet, partly decoupled part in northern Tibet, and the coupled part under the Tarim basin. The different P-wave anisotropies and velocity anomalies in the crust reflect complex crustal flows. In the upper mantle, the ILM is underthrusting subhorizontally to the JRS, and several notable seismic anomalies are revealed in the northernmost part of the ILM. Such anomalies could be attributed to the reconstruction by the upper mantle materials in Qiangtang and Songpan-Ganzi. These different seismic features support our interpretation that the partly decoupled segment (QB and SB) is a passively squeezed layer between the ILM and the Tarim lithosphere as well as a transitional layer that rebuilds the northward underthrusting Indian plate and facilitates the 
clockwise rotation of the Tarim basin.

\section{Acknowledgements.}

This work was supported by the Strategic Priority Research Program (B) of the Chinese Academy of Sciences (Grant No. XDB03010702), National Science Foundation of China (Grant No. 41404079) and the NSFC Innovation Research Group Fund (Grant No. 41321061), and the Japanese MEXT (grant No. 26106005). Some of the instruments used were provided by the Institute of Geology and Geophysics, Chinese Academy of Science. We thank two anonymous reviewers for their constructive comments and suggestions that have improved the manuscript. The Seismic Handler and Crazyseismic software package were used for the arrival-time picking. All the figures were made using the Generic Mapping Tools package (Wessel and Smith, 1998).

\section{References}

Avouac, J.P., Tapponnier, P., Bai, M., You, H., Wang, G., 1993. Active Thrusting and Folding Along the Northern Tien-Shan and Late Cenozoic Rotation of the Tarim Relative to Dzungaria and Kazakhstan. J Geophys Res-Sol Ea 98, 6755-6804.

Chung, S.L., Chu, M.F., Zhang, Y.Q., Xie, Y.W., Lo, C.H., Lee, T.Y., Lan, C.Y., Li, X.H., Zhang, Q., Wang, Y.Z., 2005. Tibetan tectonic evolution inferred from spatial and temporal variations in post-collisional magmatism. Earth-Sci Rev 68, 173-196.

Clark, M.K., Royden, L.H., 2000. Topographic ooze: Building the eastern margin of Tibet by lower crustal flow. Geology 28, 703-706.

Craig, T.J., Copley, A., Jackson, J., 2012. Thermal and tectonic consequences of India underthrusting Tibet. Earth Planet Sc Lett 353, 231-239.

Eberhart-Phillips, D., Henderson, C.M., 2004. Including anisotropy in 3-D velocity inversion and application to Marlborough, New Zealand. Geophys J Int 156, 237-254.

England, P., Houseman, G., 1986. Finite Strain Calculations of Continental Deformation .2. Comparison with the India-Asia Collision Zone. J Geophys Res-Solid 91, 3664-3676.

Furuya, M., Yasuda, T., 2011. The 2008 Yutian normal faulting earthquake (Mw 7.1), NW Tibet: Non-planar fault modeling and implications for the Karakax Fault. Tectonophysics $511,125-133$.

Hacker, B.R., Abers, G.A., 2004. Subduction Factory 3: An Excel worksheet and macro for calculating the densities, seismic wave speeds, and $\mathrm{H} 2 \mathrm{O}$ contents of minerals and rocks at 
pressure and temperature. Geochem Geophy Geosy 5.

Hearn, T.M., 1996. Anisotropic Pn tomography in the western United States. J Geophys Res-Sol Ea 101, 8403-8414.

Huang, W.C., Ni, J.F., Tilmann, F., Nelson, D., Guo, J.R., Zhao, W.J., Mechie, J., Kind, R., Saul, J., Rapine, R., Hearn, T.M., 2000. Seismic polarization anisotropy beneath the central Tibetan Plateau. J Geophys Res-Sol Ea 105, 27979-27989.

Kapp, P., Taylor, M., Stockli, D., Ding, L., 2008. Development of active low-angle normal fault systems during orogenic collapse: Insight from Tibet (vol 36, pg no 7, 2008). Geology 36, 336-336.

Kapp, P., Yin, A., Manning, C.E., Harrison, T.M., Taylor, M.H., Ding, L., 2003. Tectonic evolution of the early Mesozoic blueschist-bearing Qiangtang metamorphic belt, central Tibet. Tectonics 22 .

Karato, S., Jung, H., Katayama, I., Skemer, P., 2008. Geodynamic significance of seismic anisotropy of the upper mantle: New insights from laboratory studies. Annu Rev Earth Pl Sc 36, 59-95.

Kennett, B.L.N., Engdahl, E.R., 1991. Traveltimes for Global Earthquake Location and Phase Identification. Geophys J Int 105, 429-465.

Laske, G., Masters, G., Ma, Z.T., Pasyanos, M., 2013. Update on CRUST1.0 - a 1-degree Global Model of Earth's Crust. Abstract presented at 2013, EGU, Vienna, Austria, id: EGU2013-2658.

Lee, C.T.A., 2003. Compositional variation of density and seismic velocities in natural peridotites at STP conditions: Implications for seismic imaging of compositional heterogeneities in the upper mantle. J Geophys Res-Sol Ea 108.

Liu, X., Zhao, D., Li, S., 2013. Seismic heterogeneity and anisotropy of the southern Kuril arc: insight into megathrust earthquakes. Geophys. J. Int. 194, 1069-1090.

McKenzie, D., Priestley, K., 2008. The influence of lithospheric thickness variations on continental evolution. Lithos 102, 1-11.

Niu, X., Zhao, D., Li, J., Ruan, A., 2016. P wave azimuthal and radial anisotropy of the Hokkaido subduction zone. J. Geophys. Res. Solid Earth 121, 2536-2660.

Paige, C.C., Saunders, M.A., 1982. Lsqr - an Algorithm for Sparse Linear-Equations and Sparse Least-Squares. Acm T Math Software 8, 43-71.

Priestley, K., Debayle, E., McKenzie, D., Pilidou, S., 2006. Upper mantle structure of eastern Asia from multimode surface waveform tomography. J Geophys Res-Sol Ea 111, doi:10.1029/2005JB004082.

Rapine, R.R., Ni, J.F., Hearn, T.M., 1997. Regional wave propagation in China and its surrounding regions. B Seismol Soc Am 87, 1622-1636.

Raterman, N.S., Cowgill, E., Lin, D., 2007. Variable structural style along the Karakoram fault explained using triple-junction analysis of intersecting faults. Geosphere 3, 71-85.

Razi, A.S., Levin, V., Roecker, S.W., Huang, G.C.D., 2014. Crustal and uppermost mantle structure beneath western Tibet using seismic traveltime tomography. Geochem Geophy Geosy 15, 434-452.

Styron, R., Taylor, M., Sundell, K., 2015. Accelerated extension of Tibet linked to the northward underthrusting of Indian crust. Nat Geosci 8, 131-134.

Taylor, M., Peltzer, G., 2006. Current slip rates on conjugate strike-slip faults in central Tibet 
using synthetic aperture radar interferometry. J Geophys Res-Sol Ea 111.

Taylor, M., Yin, A., Ryerson, F.J., Kapp, P., Ding, L., 2003. Conjugate strike-slip faulting along the Bangong-Nujiang suture zone accommodates coeval east-west extension and north-south shortening in the interior of the Tibetan Plateau (vol 22, art no 1044, 2003). Tectonics 22.

Tian, Y., Zhao, D., 2012. Seismic anisotropy and heterogeneity in the Alaska subduction zone. Geophys. J. Int. 190, 629-649.

Tilmann, F., Ni, J., Team, I.I.S., 2003. Seismic imaging of the downwelling Indian lithosphere beneath central Tibet. Science 300, 1424-1427.

Van Buer, N.J., Jagoutz, O., Upadhyay, R., Guillong, M., 2015. Mid-crustal detachment beneath western Tibet exhumed where conjugate Karakoram and Longmu-Gozha Co faults intersect. Earth Planet. Sci. Lett. 413, 144-157.

Wang, J., Wu, H.H., Zhao, D.P., 2014. P wave radial anisotropy tomography of the upper mantle beneath the North China Craton. Geochem. Geophy. Geosyst. 15, 2195-2210.

Wang, J., Zhao, D.P., 2008. P-wave anisotropic tomography beneath Northeast Japan. Phys. Earth Planet. Inter. 170, 115-133.

Wang, J., Zhao, D.P., 2013. P-wave tomography for 3-D radial and azimuthal anisotropy of Tohoku and Kyushu subduction zones. Geophys. J. Int. 193, 1166-1181.

Wessel, P., Smith, W., 1998. New, improved version of Generic Mapping Tools released. Eos Trans. AGU, 79, 579.

Wittlinger, G., Vergne, J., Tapponnier, P., Farra, V., Poupinet, G., Jiang, M., Su, H., Herquel, G., Paul, A., 2004. Teleseismic imaging of subducting lithosphere and Moho offsets beneath western Tibet. Earth Planet Sc Lett 221, 117-130.

Wu, J., Zhang, Z.J., Kong, F.S., Yang, B.B., Yu, Y.G., Liu, K.H., Gao, S.S., 2015. Complex seismic anisotropy beneath western Tibet and its geodynamic implications. Earth Planet Sc Lett 413, 167-175.

Xu, Z.Q., He, B.Z., Zhang, C.L., Zhang, J.X., Wang, Z.M., Cai, Z.H., 2013. Tectonic framework and crustal evolution of the Precambrian basement of the Tarim Block in NW China: New geochronological evidence from deep drilling samples. Precambrian Res 235, 150-162.

Yin, A., Harrison, T.M., 2000. Geologic evolution of the Himalayan-Tibetan orogen. Annu Rev Earth Pl Sc 28, 211-280.

Yin, A., Taylor, M.H., 2011. Mechanics of V-shaped conjugate strike-slip faults and the corresponding continuum mode of continental deformation. Geol Soc Am Bull 123, 1798-1821.

Yu, C.Q., Zheng, Y.C., Shang, X.F., 2016. Crazyseismic: A MATLAB-GUI based software for passive seismic data preprocessing. Submitted to Seismol. Res. Lett.

Zhang, H., Zhao, D.P., Zhao, J.M., Xu, Q., 2012a. Convergence of the Indian and Eurasian plates under eastern Tibet revealed by seismic tomography. Geochem Geophy Geosy 13, doi:10.1029/2012GC004031.

Zhang, H., Zhao, J.M., Xu, Q., 2012b. Crustal and upper mantle velocity structure beneath central Tibet by P-wave teleseismic tomography. Geophys J Int 190, 1325-1334.

Zhang, L.T., Unsworth, M., Jin, S., Wei, W.B., Ye, G.F., Jones, A.G., Jing, J.N., Dong, H., Xie, C.L., Le Pape, F., Vozar, J., 2015. Structure of the Central Altyn Tagh Fault revealed by 
magnetotelluric data: New insights into the structure of the northern margin of the India-Asia collision. Earth Planet Sc Lett 415, 67-79.

Zhang, Z.J., Wang, Y.H., Houseman, G.A., Xu, T., Wu, Z.B., Yuan, X.H., Chen, Y., Tian, X.B., Bai, Z.M., Teng, J.W., 2014. The Moho beneath western Tibet: Shear zones and eclogitization in the lower crust. Earth Planet Sc Lett 408, 370-377.

Zhao, D., 2015. Multiscale Seismic Tomography. Springer, 304 pp., New York.

Zhao, D.P., Hasegawa, A., Horiuchi, S., 1992. Tomographic imaging of P and S wave velocity structure beneath northeastern Japan. J. Geophys. Res. 97, 19909-19928.

Zhao, D.P., Hasegawa, A., Kanamori, H., 1994. Deep structure of Japan subduction zone as derived from local, regional, and teleseismic events. J. Geophys. Res. 99, 22313-22329.

Zhao, D.P., Yu, S., Liu, X., 2016. Seismic anisotropy tomography: New insight into subduction dynamics. Gondwana Res. 33, 24-43.

Zhao, J.M., Yuan, X.H., Liu, H.B., Kumar, P., Pei, S.P., Kind, R., Zhang, Z.J., Teng, J.W., Ding, L., Gao, X., Xu, Q., Wang, W., 2010. The boundary between the Indian and Asian tectonic plates below Tibet. P Natl Acad Sci USA 107, 11229-11233.

\section{Figure Caption}

Figure 1. (a) Map of the study region. The black lines denote the tectonic block boundaries. The red triangles show the portable seismic stations of the ANTILOPE-I project. The open circles and diamonds denote the local earthquakes generating P- and S-wave data, respectively. The green dashed line (A-B) shows the location of the vertical cross-section in Fig. 6. MBT, the Main Boundary Thrust; ITS, the Indus-Tsangpo suture; BNS, the Bangong-Nujiang suture; JRS, the Jinsha River suture; ATF, the Altyn-Tagh Fault; GLF, the Gozha-Longmu Co fault system; KF, the Karakorum fault; LF, the Lungar fault; HB, the Himalaya block; LB, the Lhasa block; QB, the Qiangtang block; SB, the Songpan-ganzi block; TB, the Tarim basin. (b, c) Distribution of the teleseismic events at epicentral distances of $30^{\circ}-90^{\circ}$ which generated (b) P-wave and (c) S-wave data used in the this study. 
Figure 2. (a) The starting 1-D P-wave velocity model (the solid lines) adopted for the 3-D tomographic inversion. The dashed lines denote the modified CRUST1.0 model (see text for details). (b) Vertical distribution of grid nodes in the east-west direction, which are adopted for the tomographic inversion. (c) Vertical distribution of grid nodes in the north-south direction along $82^{\circ} \mathrm{E}$ longitude. (d) A map view of the grid nodes adopted for the final tomographic inversion. The fine grid (black dots) and the coarse grid (blue circles) are used to parameterize the 3-D isotropic and anisotropic Vp structures, respectively.

Figure 3. Map views of (a) Vp azimuthal anisotropy tomography, and (b) Vs isotropic tomography. The red and blue colors denote low and high velocities, respectively. The azimuth and length of each bar represent the fast velocity direction and anisotropic amplitude, respectively. The layer depth is shown above each map in (a). The open circles in (b) denote local earthquakes $(M \geq 3)$ that occurred during 2000 to 2015.

Figure 4. Map views of (a) Vp/Vs ratio and (b) Vp radial anisotropy tomography. The red and blue colors in (a) denote high and low values of $\mathrm{Vp} / \mathrm{Vs}$, respectively. The brown and green colours in (b) denote positive and negative radial anisotropies, respectively. The layer depth is shown above each map in (a). The open circles in (a) denote local earthquakes $(M \geq 3)$ that occurred during 2000 to 2015.

Figure 5. Map views showing the distributions of (a) $\mathrm{P}$ and (b) $\mathrm{S}$ wave travel-time 
residuals of local earthquakes in different directions. In each map, the dark sector in the circle shows the quadrant where the earthquakes are located. The cross and triangle symbols denote positive and negative residuals, respectively. Their scales are shown at the bottom.

Figure 6. Vertical cross-sections of (b) $\mathrm{Vp}$, (c) $\mathrm{Vs}$, (d) $\mathrm{V}_{\mathrm{p}} / \mathrm{V}_{\mathrm{s}}$ ratio, and (e) $\mathrm{Vp}$ radial anisotropy tomography along the profile A-B shown in Fig. 1a. The surface topography along the profile is shown in (a). Their perturbation scales are shown at the bottom. The solid and dashed lines denote the Moho discontinuity and the Indian lithosphere-asthenosphere boundary, respectively, which are derived from the receiver-function results (Zhao et al., 2010). The open circles denote local earthquakes $(M \geq 3)$ that occurred within a 50-km width of the profile.

Figure 7. (a-c) Map views and (d-f) north-south vertical cross-sections along $82^{\circ} \mathrm{E}$ longitude showing the results of checkerboard resolution tests for (a) Vp azimuthal anisotropy tomography, (d) Vp isotropic tomography, (b, e) Vs tomography, and (c, f) Vp radial anisotropy tomography. The layer depth is shown above each map in (a). The red and blue colors in (a, b, d, e) denote slow and fast velocity perturbations, respectively. The red color in (c, f) denotes negative radial anisotropy (i.e., vertical $\mathrm{V}_{\mathrm{p}}>$ horizontal $\mathrm{V}_{\mathrm{p}}$ ), whereas the blue color in $(\mathrm{c}, \mathrm{f})$ denotes positive radial anisotropy (i.e., vertical $\mathrm{V}_{\mathrm{p}}<$ horizontal $\mathrm{V}_{\mathrm{p}}$ ). The azimuth and length of each bar in (a) represent the fast-velocity direction and anisotropic amplitude, respectively. The white lines in 
(a-c) denote tectonic block boundaries in the study region. The scales for the velocity perturbation and Vp anisotropy are shown below (f).

Figure 8. A schematic diagram illustrating a geodynamic model of the western Tibetan Plateau. The black arrows at the surface indicate the fast-velocity directions of P-wave azimuthal anisotropy in the crust. The bold circle shows a weak azimuthal anisotropy in the crust. The black dotted line denotes the Altyn-Tagh Fault. The color bold arrows indicate the fast-velocity directions of P-wave azimuthal anisotropy in the upper mantle. 
(a)

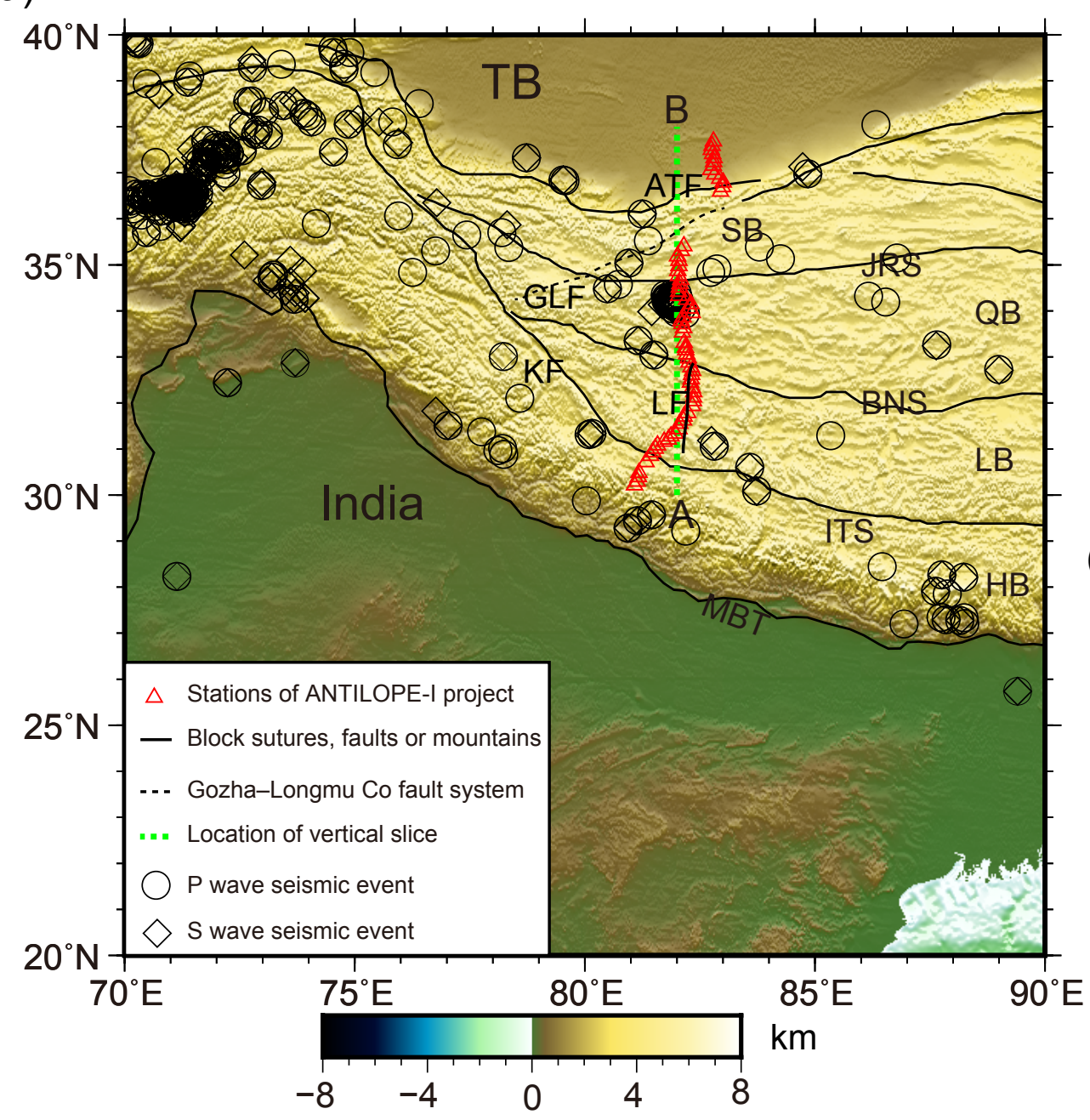

(b)
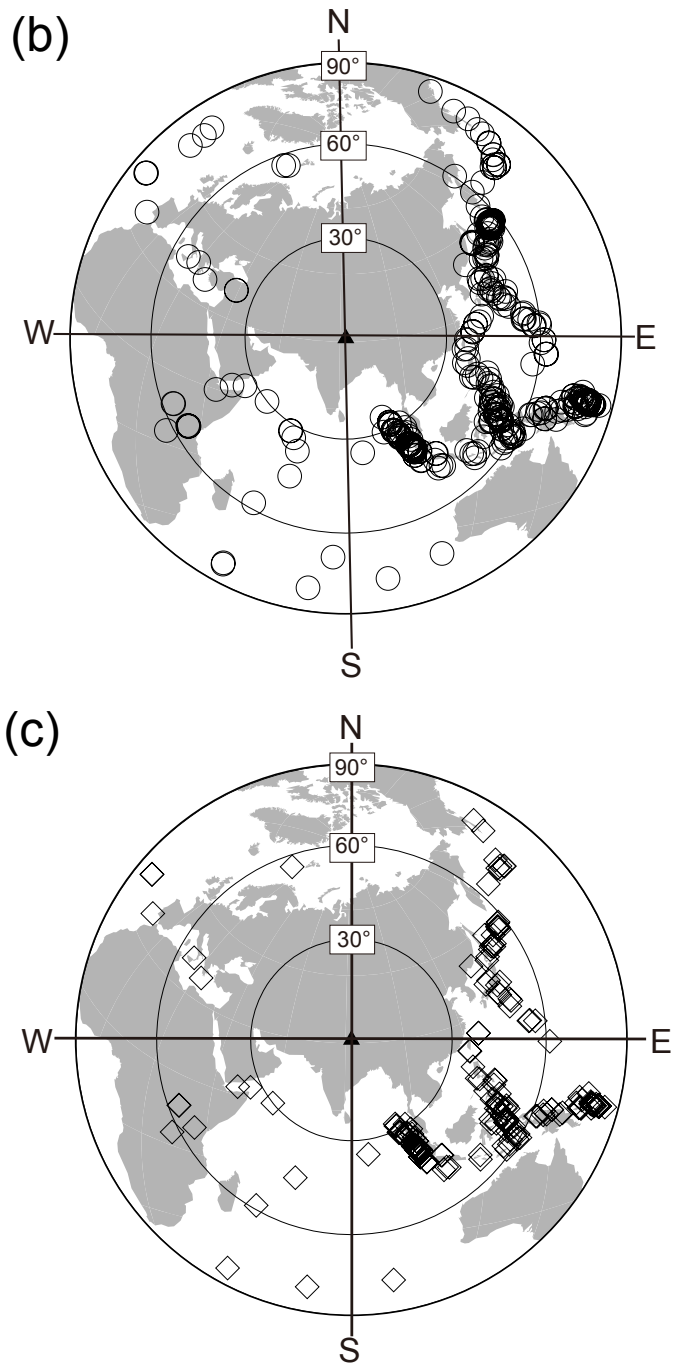


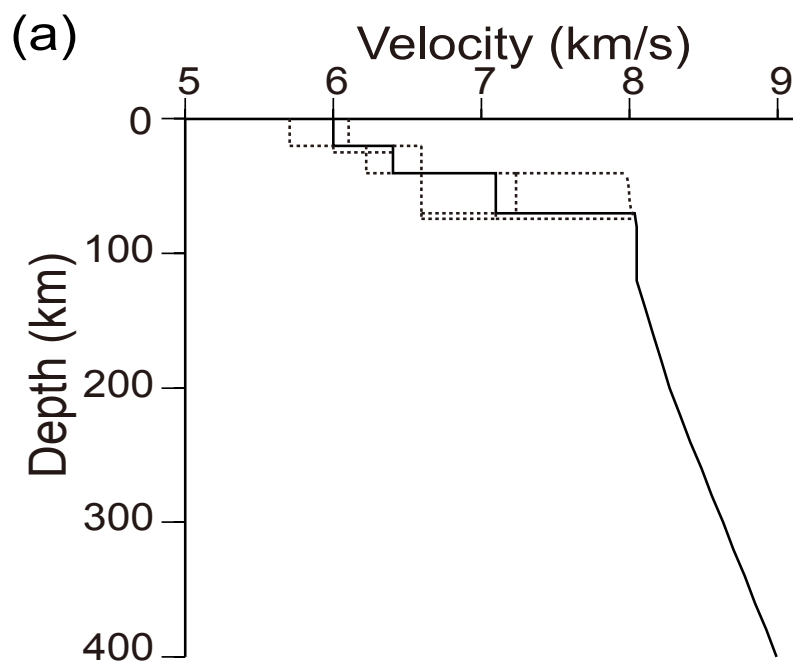

(b)

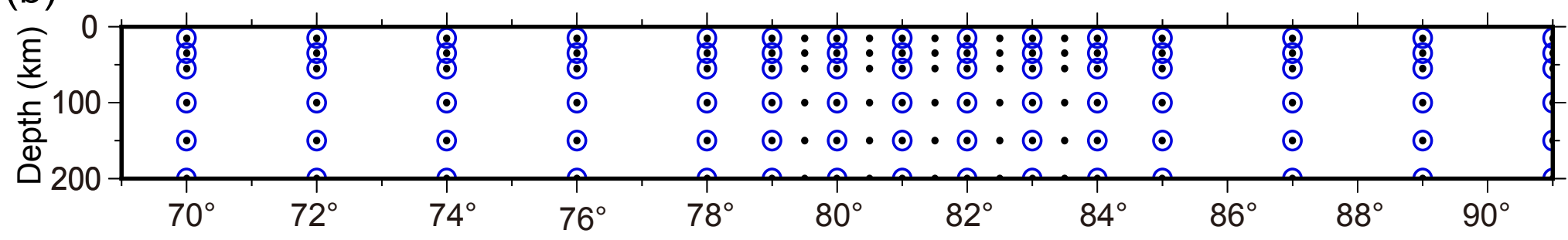

(c)

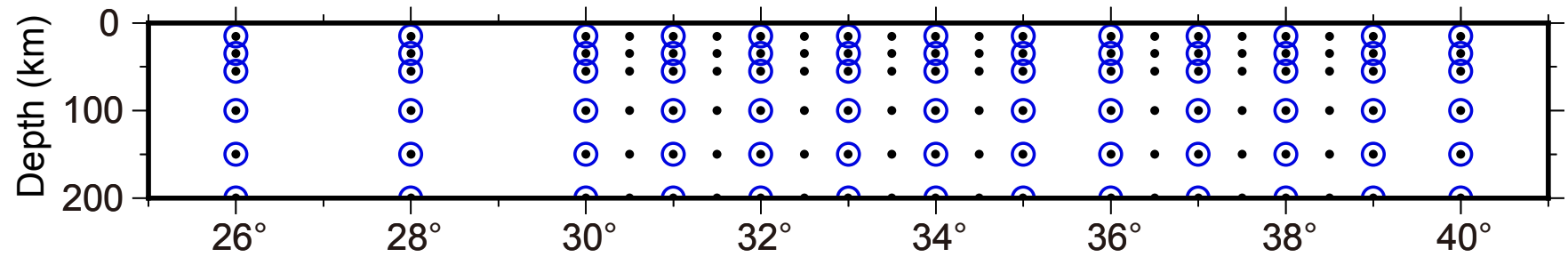

(d)

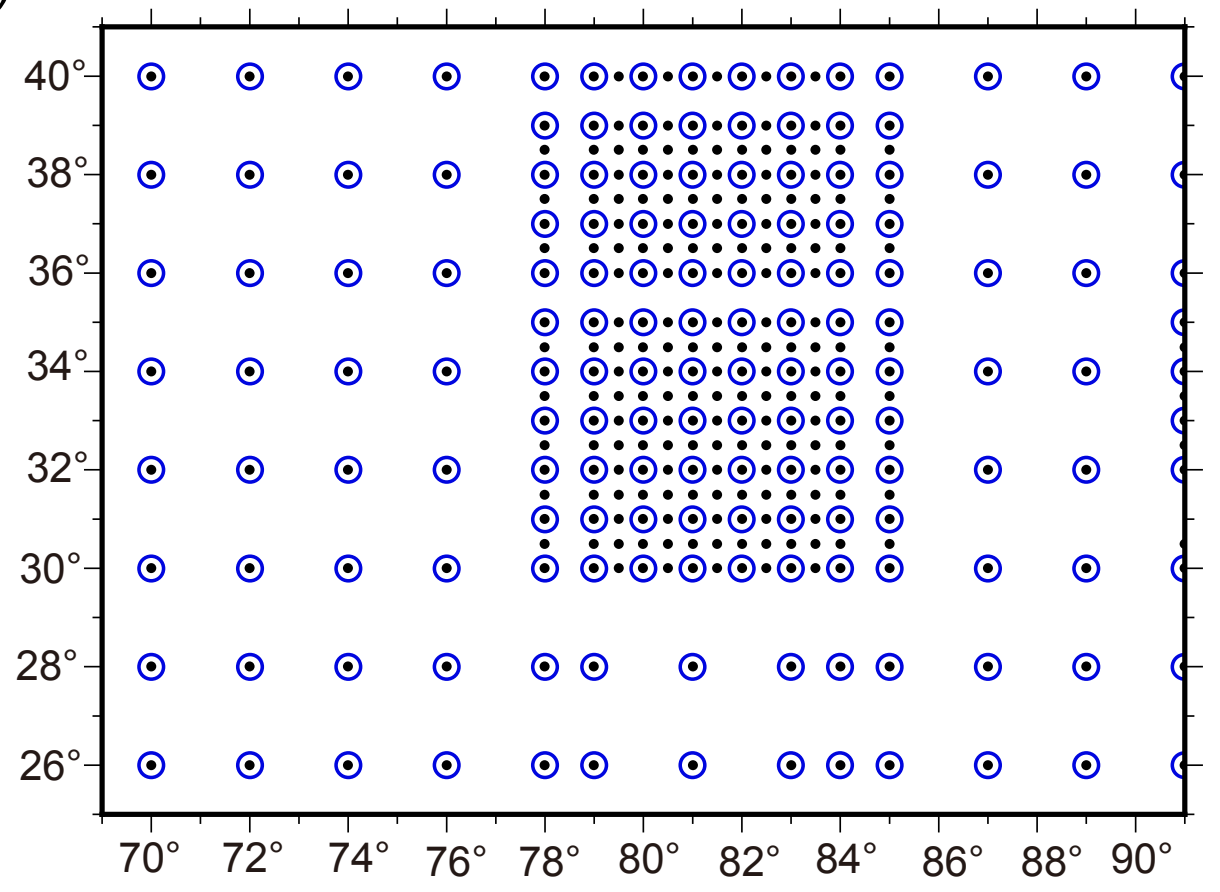


(a) $\mathrm{Vp}$ and azimuthal anisotropy
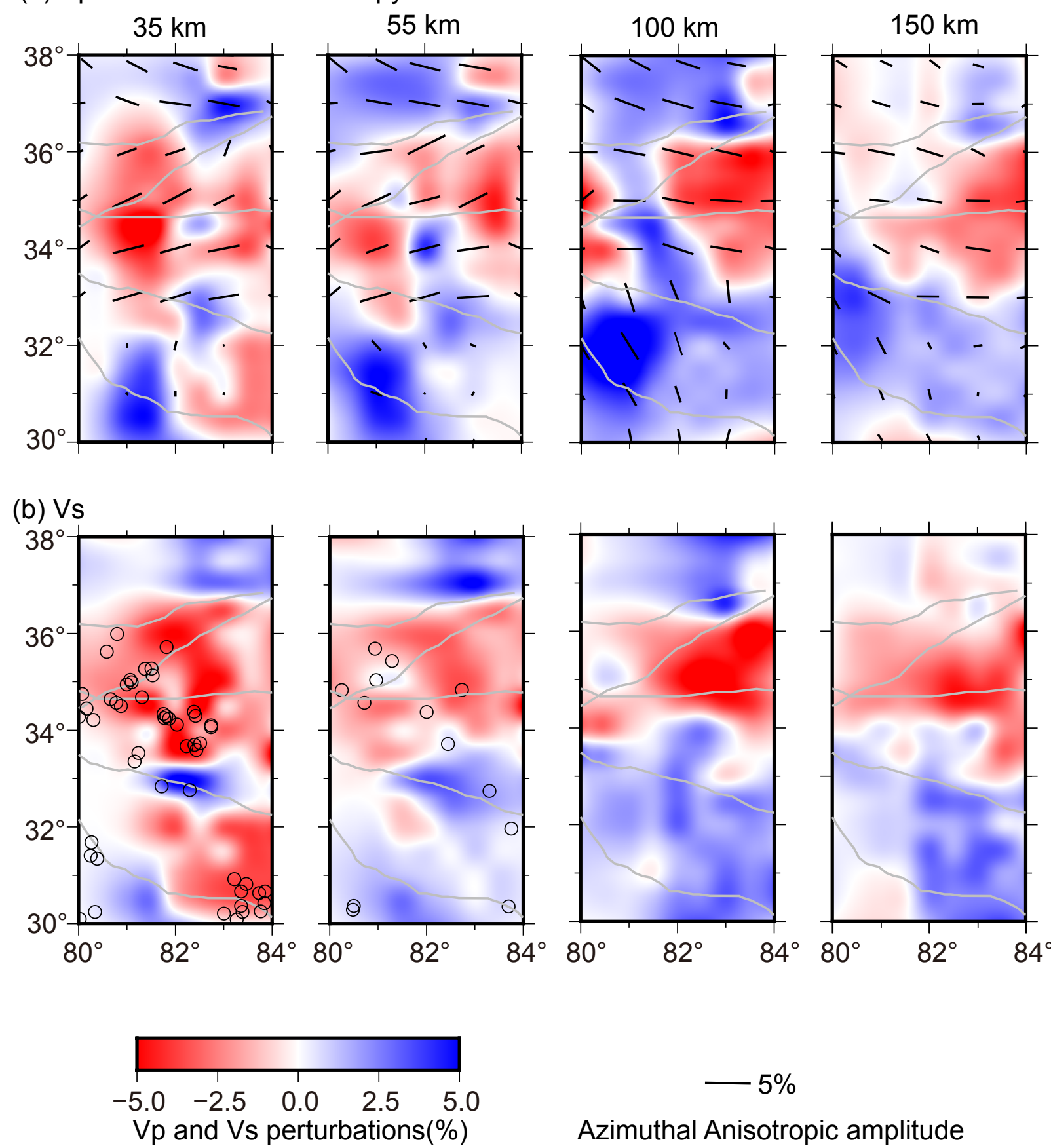

$$
-5 \%
$$

Azimuthal Anisotropic amplitude 
(a) $\mathrm{Vp} / \mathrm{Vs}$
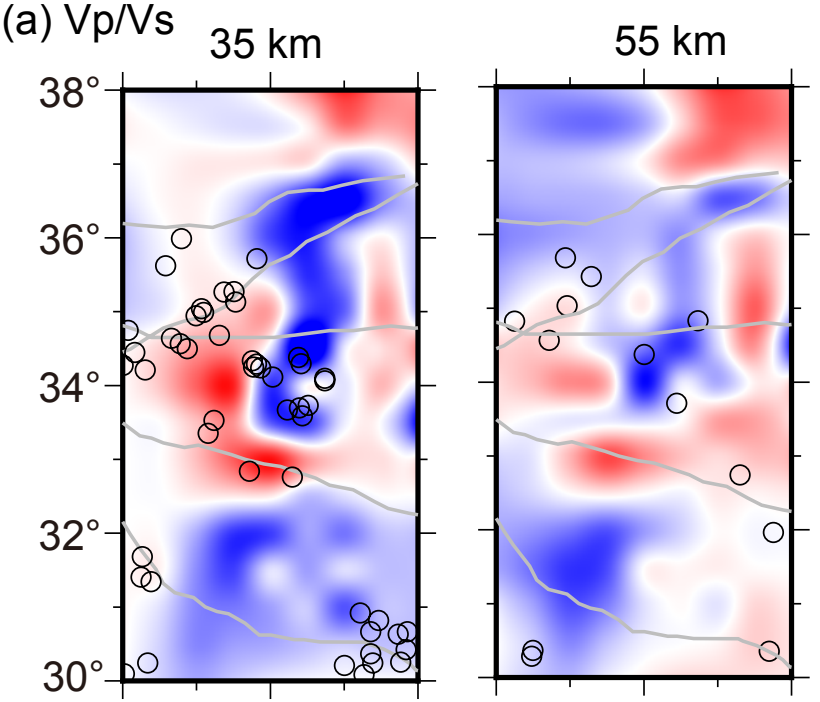

$150 \mathrm{~km}$
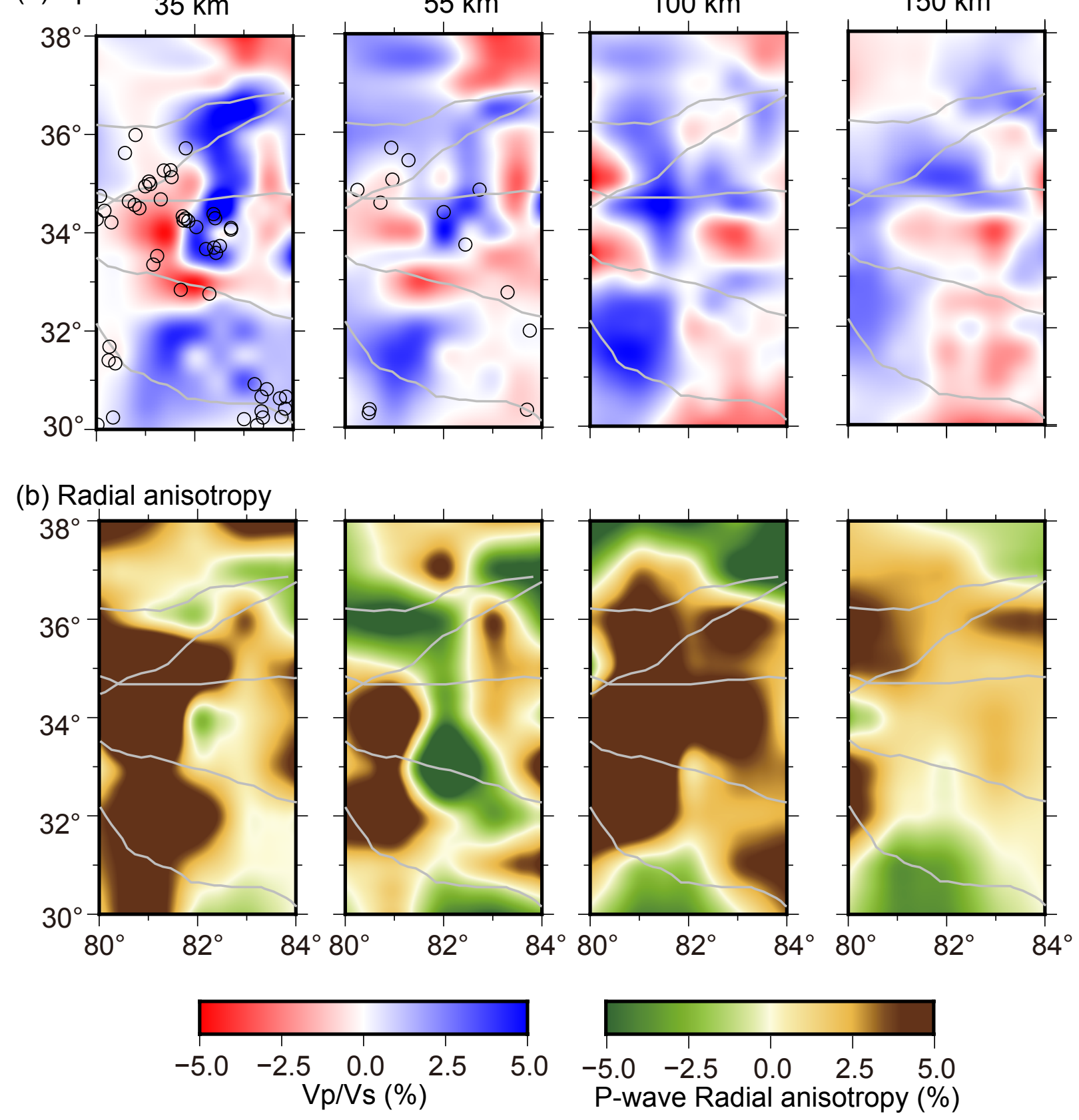
(a) P-wave travel time residuals
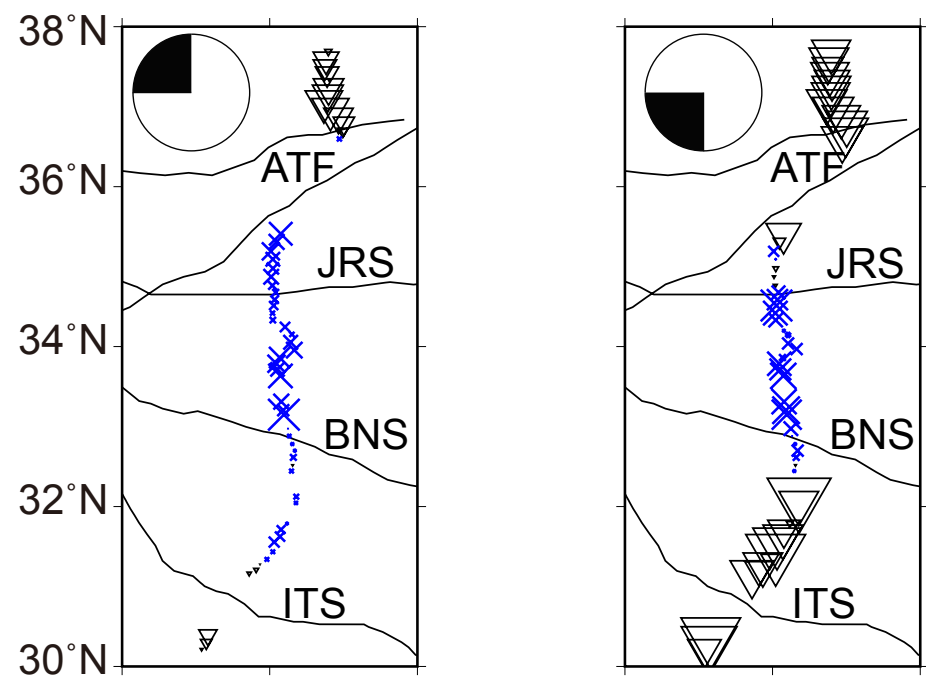

(b) S-wave travel time residuals
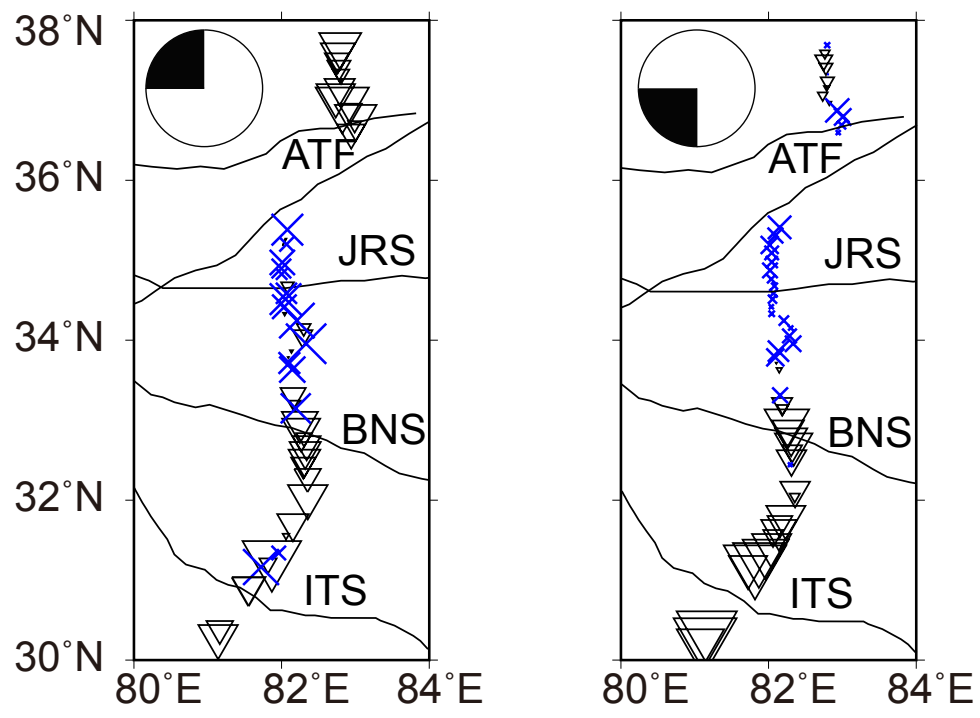

$\nabla-1.5 \mathrm{~s} \quad \times 1.5 \mathrm{~s}$ 
(a)

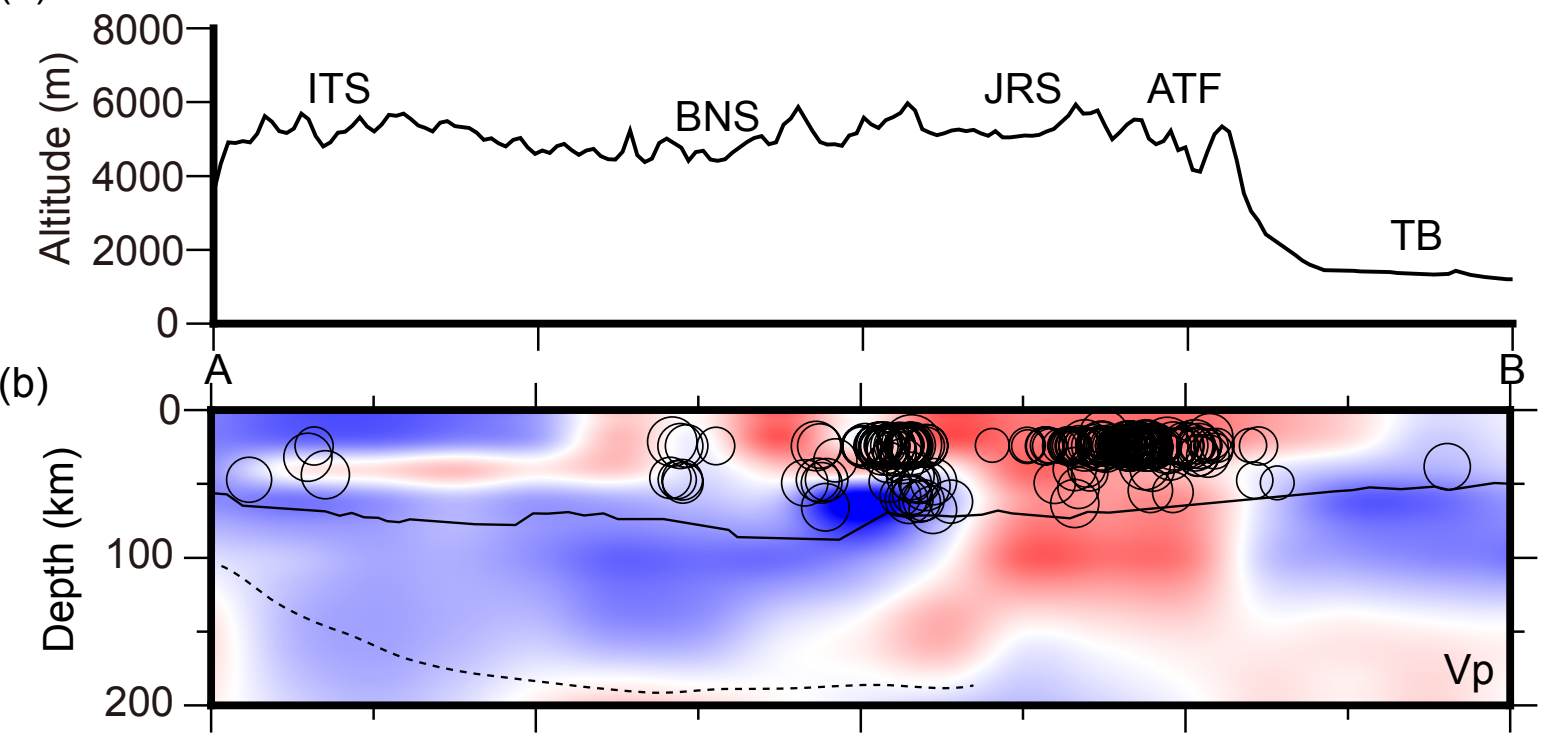

(c)

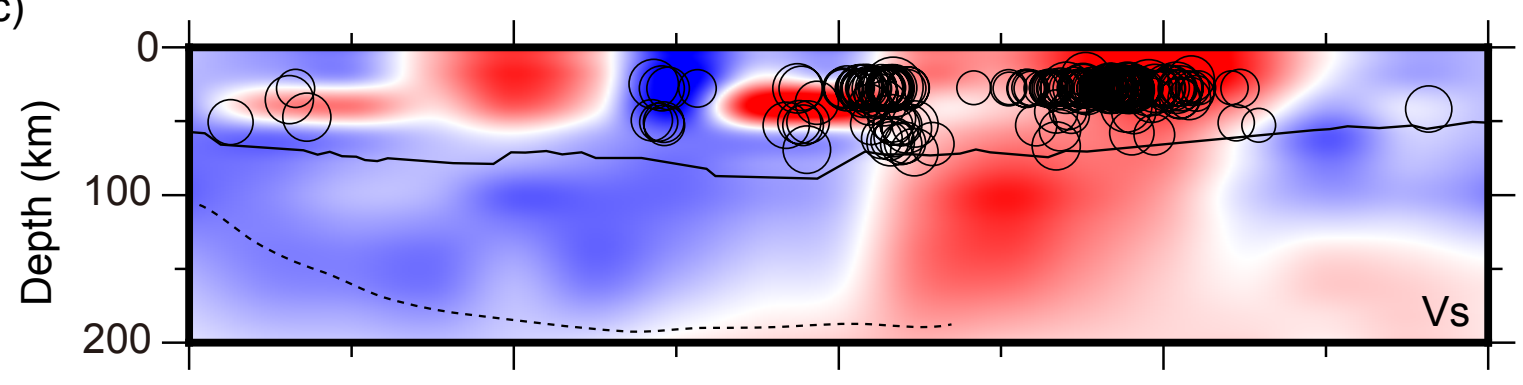

(d)

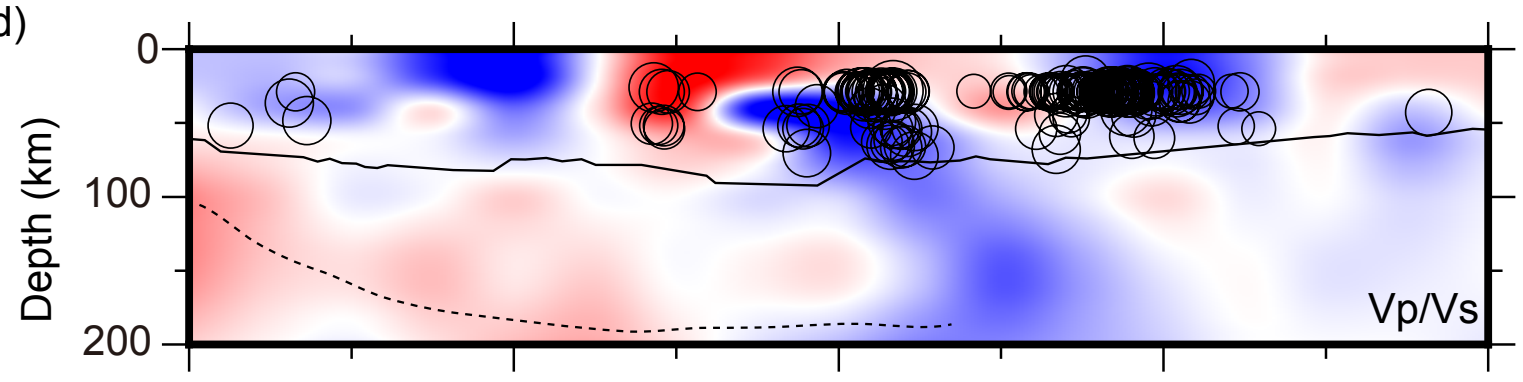

(e)
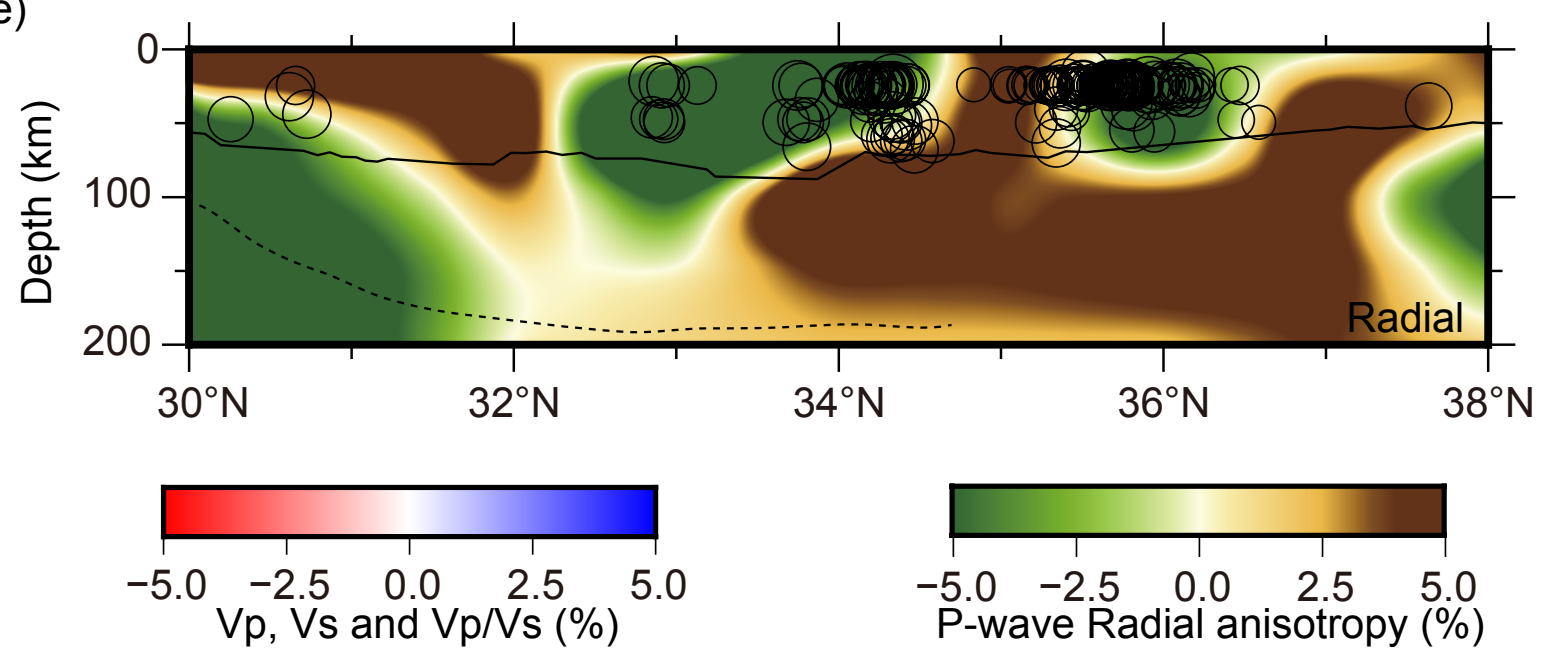

$\begin{array}{lllll}-5.0 & -2.5 & 0.0 & 2.5 & 5.0\end{array}$

P-wave Radial anisotropy (\%) $\bigcirc \bigcirc \bigcirc$

Magnitude of local earthquakes (Mb) 
(a) Vp and azimuthal anisotropy
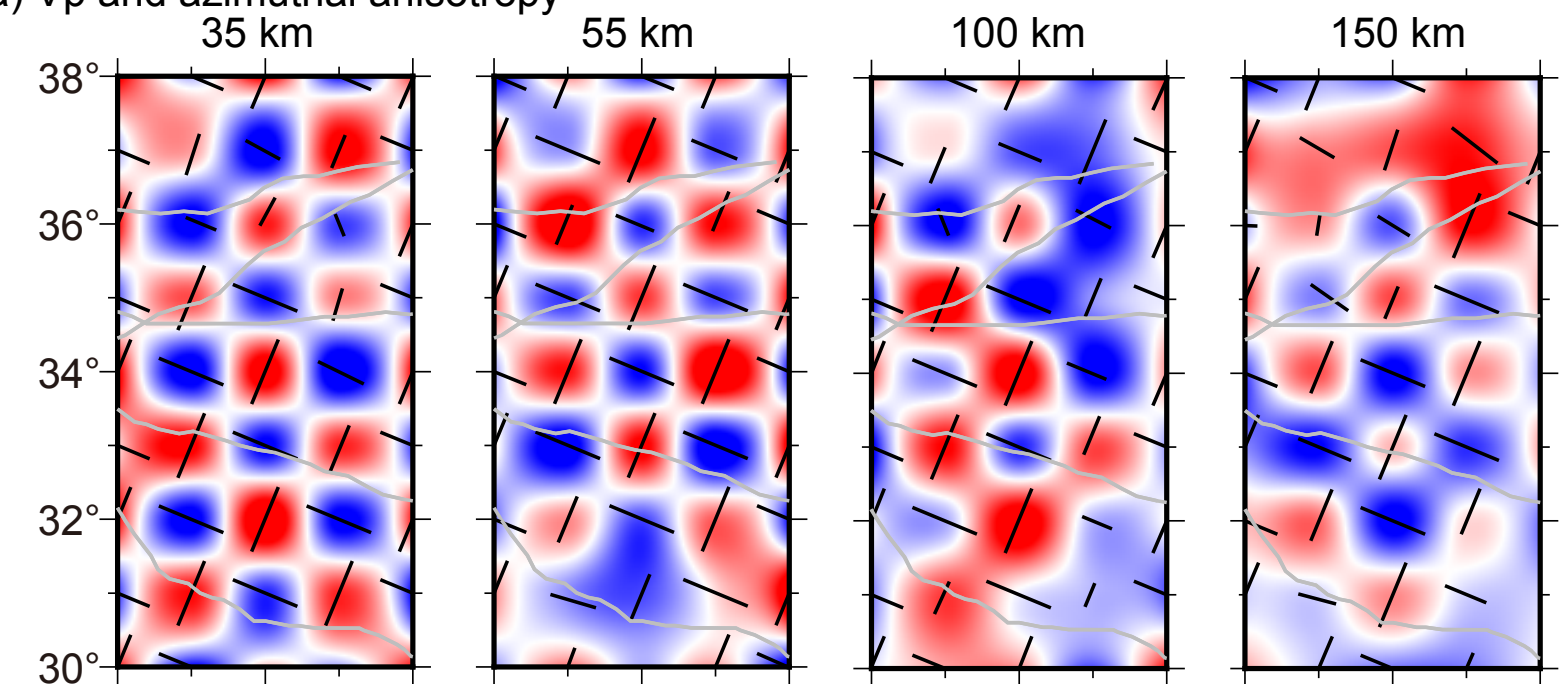

(b) $\mathrm{Vs}$
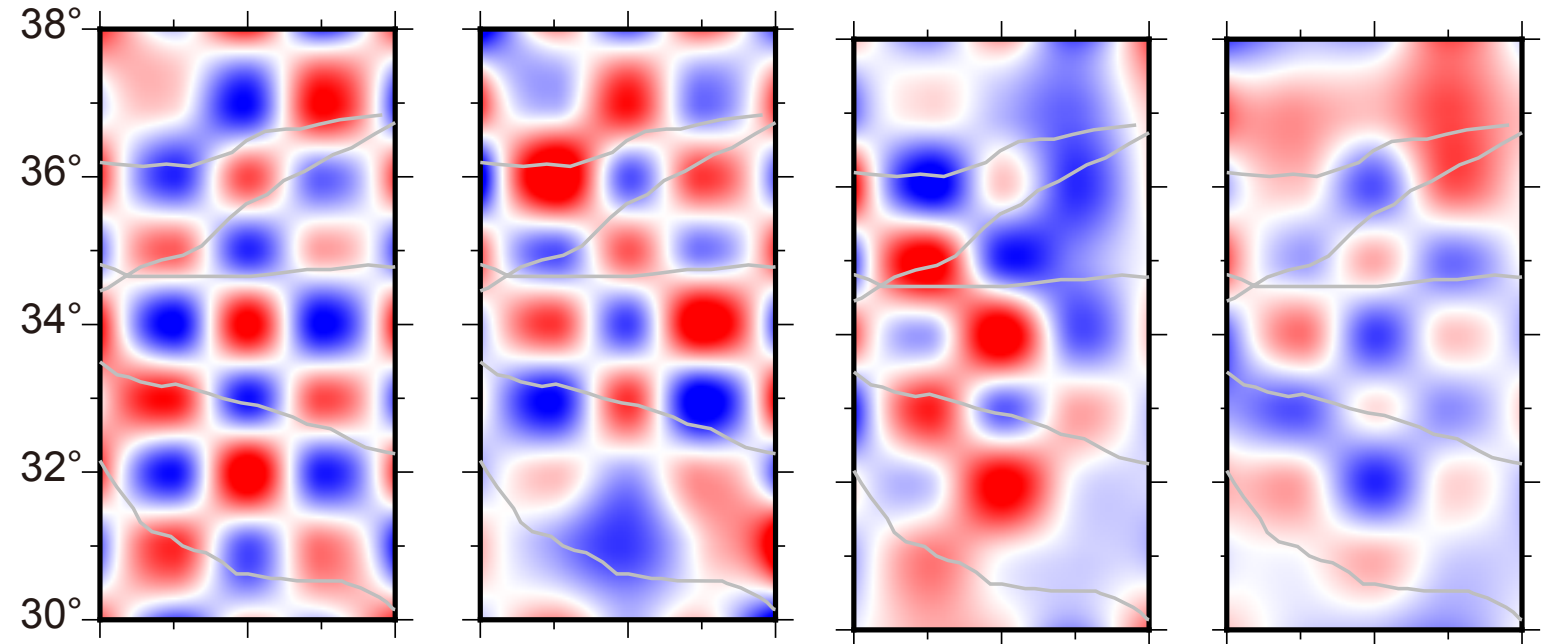

(c) Radial

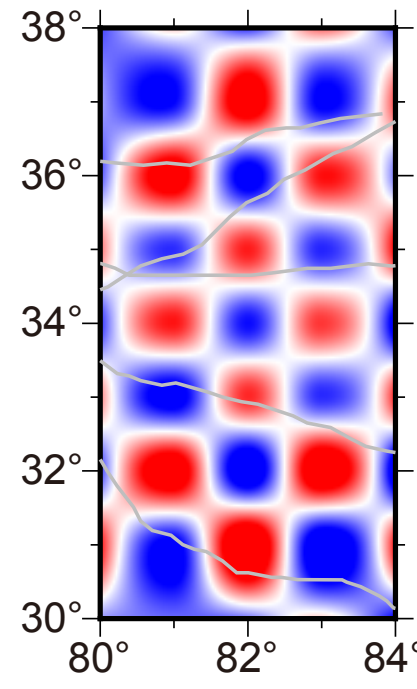

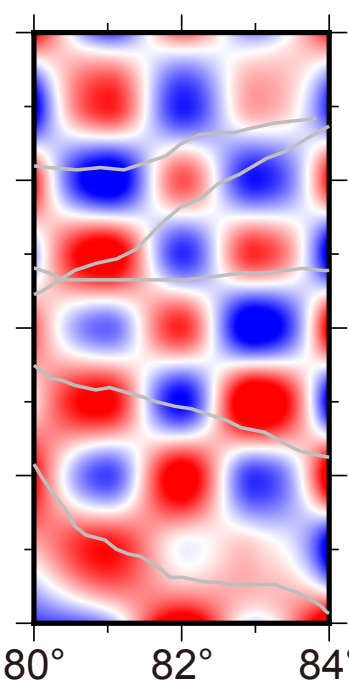



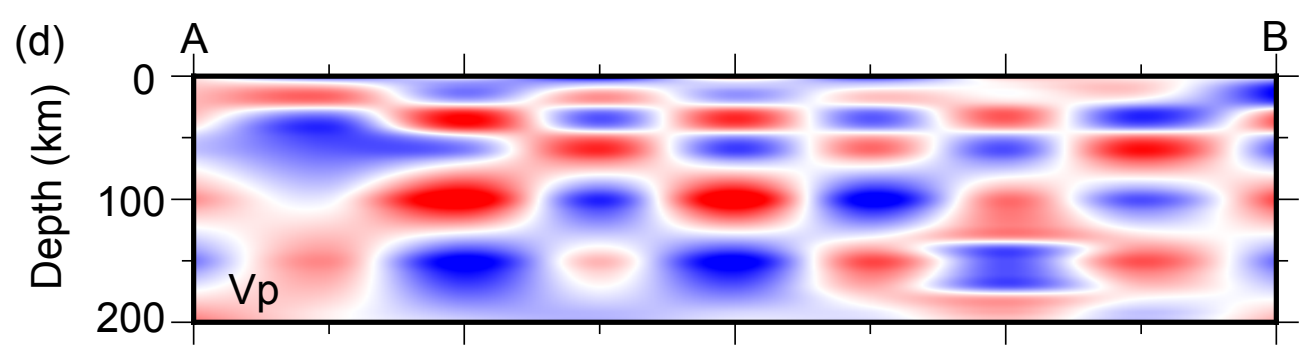
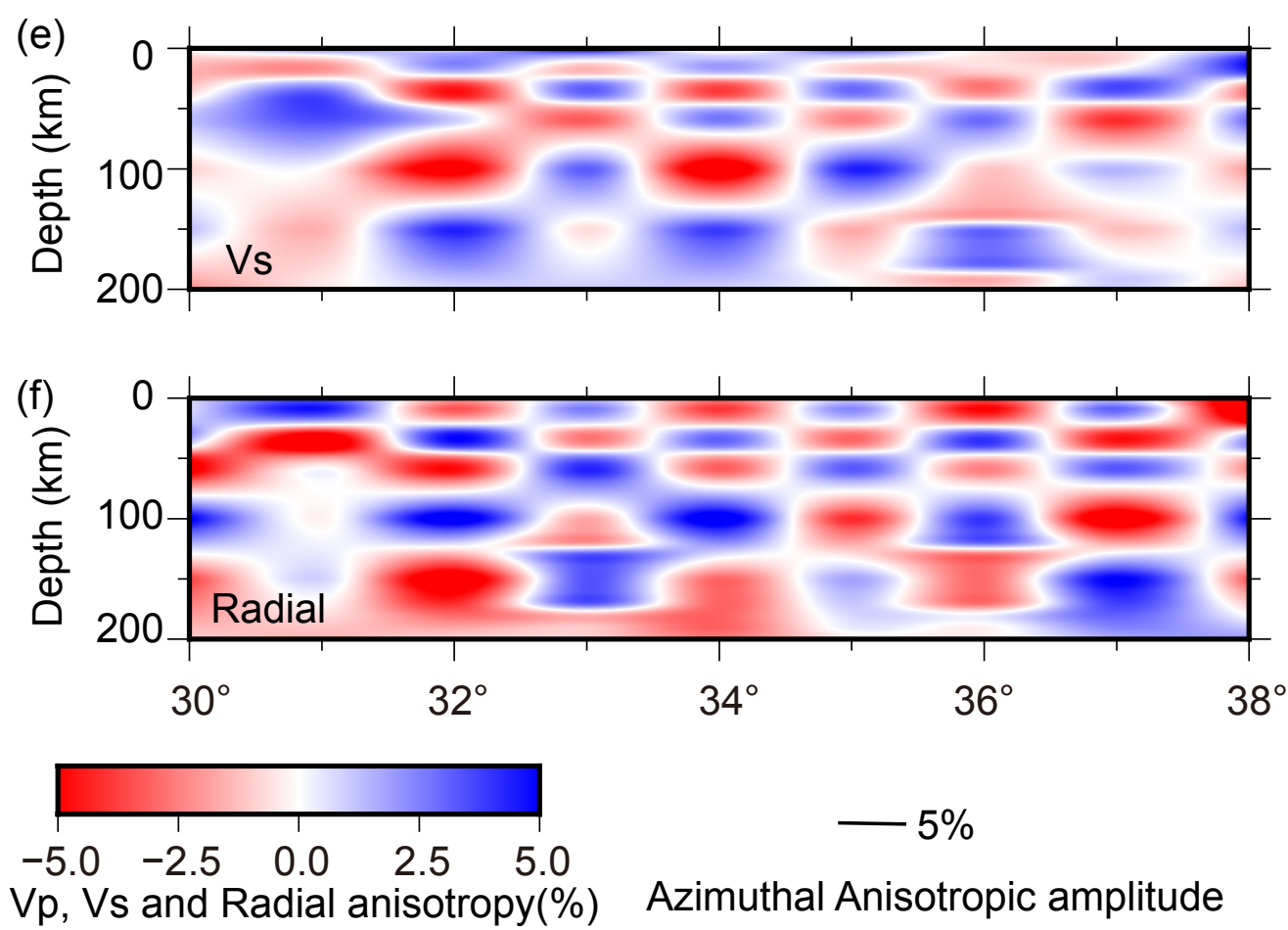


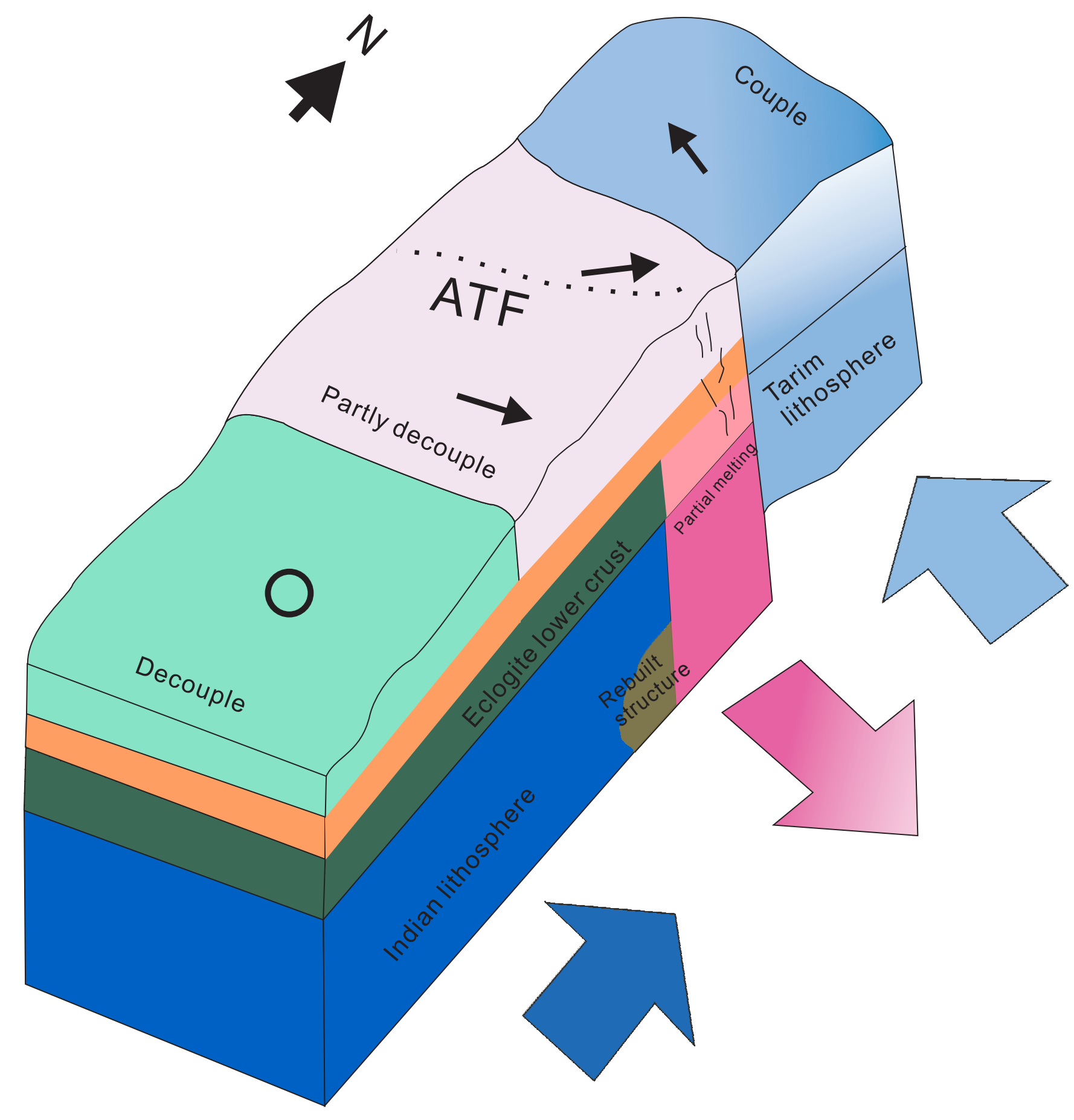




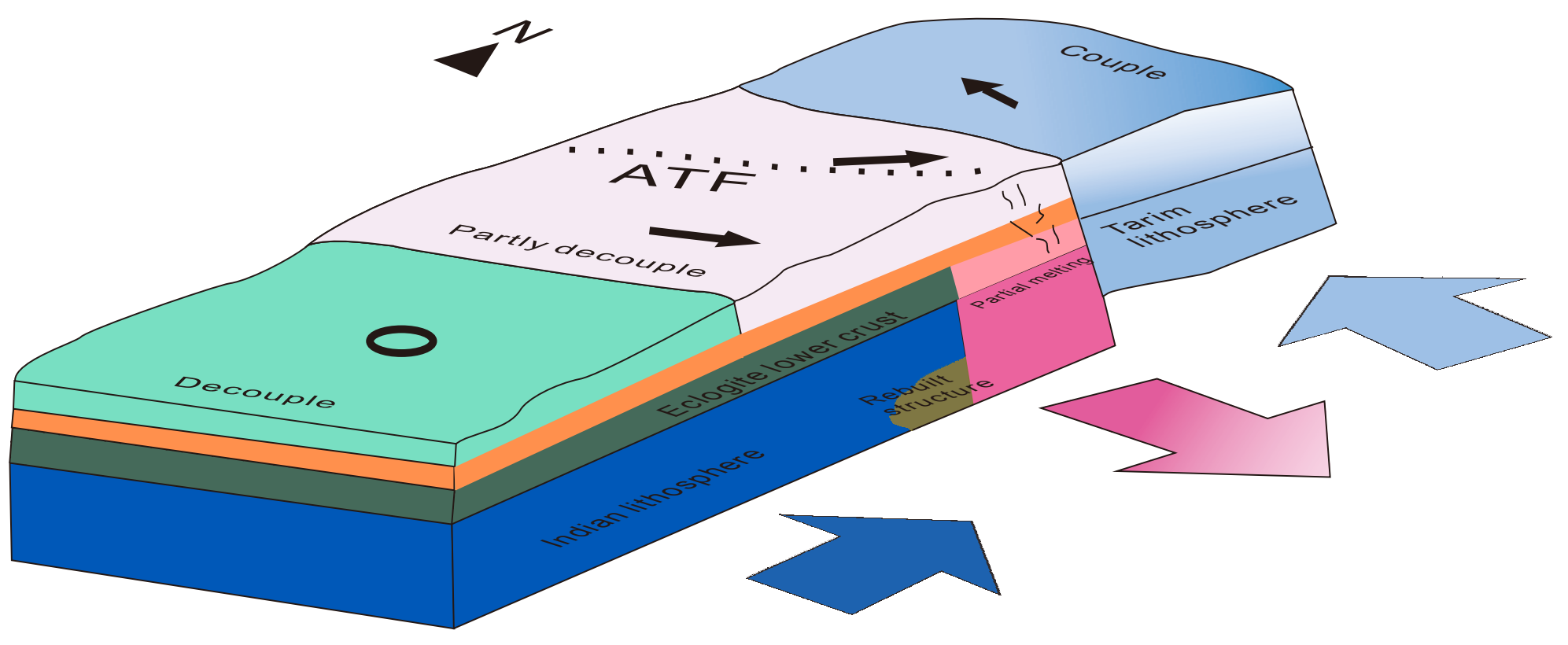

